\title{
Vaporization model for arsenic during single-particle coal combustion:
}

\section{Model development}

\author{
Huimin Liu ${ }^{\mathrm{a}}$, Chunbo Wang ${ }^{\mathrm{a}}$, Yue Zhang ${ }^{\mathrm{a}}$, Chan Zou ${ }^{\mathrm{a}}$, Edward Anthony, \\ a Department of Energy Power \& Mechanical Engineering, North China Electric Power \\ University, Baoding 071003, China \\ b School of Power Engineering, Cranfield University, Cranfield, Bedfordshire MK43 0AL, UK \\ * Corresponding author: b.j.anthony@cranfield.ac.uk
}

Abstract: The kinetic parameters for chemical reactions associated with the vaporization of arsenic species are rarely reported due to the difficulties in obtaining suitably purified arsenic compounds as well as the issues associated with the extreme toxicity of many arsenic species. Here, we used a single-particle coal combustion model combined with a vaporization yield model of arsenic fitted by experimental data, which was used to determine the activation energy and frequency factor of the oxidation/decomposition reactions of arsenic species in this work, namely: As-org, $\mathrm{FeAsS}, \mathrm{FeAsO}_{4}$ and $\mathrm{Ca}_{3}\left(\mathrm{AsO}_{4}\right)_{2}$. The combustion kinetics of volatile/char and arsenic thermodynamic properties were used to model the vaporization zone and intensity of emissions for arsenic compounds. The results show that the reaction kinetic parameters of these arsenic species could be determined within an order of magnitude despite the variation of compositions in the coal sample and temperature, and this approach provides a new method to determine the reaction kinetics of hazardous elements such as As. Combining the vaporization yield and reaction kinetics of arsenic species with the single-particle coal combustion model, a novel vaporization model of arsenic was developed. With this model, the temporal evolution of combustion parameters (temperature, conversion ratio of coal, particle porosity, flue gas concentration) as well as arsenic vaporization ratio and $\mathrm{As}_{2} \mathrm{O}_{3}(\mathrm{~g})$ concentration can be predicted at the microscopic level. Model applications and predictions can be found in Part 2 of this work [Vaporization model of arsenic during single-particle coal combustion: Part 2. Numerical simulation].

Keywords: arsenic; vaporization model; single-particle coal; combustion

\section{Introduction}

Arsenic (As) is receiving increasing attention due to its toxicity, volatility, and its bioaccumulation in the environment, combined with concerns about its potential carcinogenic 
propensities [1, 2]. As one of the main anthropogenic sources of arsenic, the behavior of arsenic in power plants is of considerable interest [3-5]. In the coal combustion process, arsenic in coal first vaporizes in the boiler, then gradually transforms into the solid phase as the temperature decreases. Some of these emissions are captured by air pollution control devices (APCDs), but inevitably some As is finally emitted with the stack gases. Tian et al. [6] studied the atmospheric emissions of arsenic in China from 2002 to 2010 by combining the detailed coal consumption data, element content in coal, and the specific emission factors which were classified by different boiler types and APCD configurations. Results showed that more than $300 \mathrm{t}$ arsenic was emitted annually in China. In 2016, EPA [7] published the latest quantitative emission limit (1.36 $\mu \mathrm{g} / \mathrm{kWh}$ ) for arsenic from coal-fired electric utility steam generating units (EGUs). The study of arsenic vaporization during coal combustion is, therefore, of great importance due to the fact that it is a key input for arsenic transformation and emissions.

Numerous studies have reported the vaporization characteristics of arsenic based on experimental measurements. The effects of coal properties [8,9], arsenic speciation [10-14], mineral components [15-17] as well as gas composition [18-20] on the vaporization ratio of arsenic have all been examined experimentally. However, all of these experiments are limited to providing a final vaporization ratio without considering how such emissions change during the coal burning process. The time-dependent profile of gaseous arsenic as well as the conversion ratio of arsenic are needed in order to better understand the vaporization behavior of arsenic in combustion processes. Liu et al. [21] and Zou et al. [22] studied changes of the vaporization ratio of arsenic by changing the residence time of coal samples. The vaporization rate of arsenic was then obtained from these data, but without information on gaseous arsenic concentrations since all the experimental tests were based on solid phase measurements. Shen et al. [23] studied the vaporization rate of arsenic in a fluidized bed with an on-line analysis system that allowed continuous monitoring of the vaporized arsenic based on inductively-coupled plasma opticalemission spectroscopy (ICP-OES). Here, the arsenic concentration in flue gas was monitored with time change; unfortunately, the combustion/pyrolysis temperature range was rather narrow ( $873 \mathrm{~K}$ to $1123 \mathrm{~K})$, due to the technical limitation of the isokinetic sampling system. In this case, a mathematical model was proposed as a useful tool to characterize the vaporization behavior of arsenic over a wide range of combustion temperatures and other conditions.

In terms of the vaporization model of arsenic, Zeng et al. [24] established the first quantitative 
physicochemical model for vaporization of arsenic during coal pyrolysis and combustion. The vaporization process for arsenic consisted of three consecutive processes: transport of molecules or atoms through the bulk pyrite liquid (melt) to the melt/gas interface; vaporization of arsenic on the melt surface; and transport of molecules/atoms through the pores of the char followed by release to the atmosphere, in which the controlling step was diffusion through the melt. This modeling approach assumed that all the arsenic in coal is associated with pyrite. However, the mode of occurrence for arsenic varies greatly with coal type and the vaporization rate of arsenic for various species may be very different from each other. For example, organic-bound arsenic is easily released into the atmosphere along with the devolatilization process [12], while arsenic which is associated with minerals in coal (e.g., in the clay mineral lattice) is always released by particle fragmentation and char combustion under relatively high temperature conditions [12]. A more detailed vaporization model for arsenic considering the vaporization difference of various arsenic species is, therefore, highly desirable. However, the key input parameters, the vaporization kinetics of arsenic-related reactions, still remain unclear due to the difficulties in obtaining pure arsenic compounds as well as due to the issues associated with the toxicity of all arsenic species (for example, the $\mathrm{LD}_{50}$ of $\mathrm{AsH}_{3}, \mathrm{As}_{2} \mathrm{O}_{3}, \mathrm{~K}_{3} \mathrm{AsO}_{4}$ and $\mathrm{Ca}_{3}\left(\mathrm{AsO}_{4}\right)_{2}$ to mice species, for which we have good data, are 3, 20, 14, and $20 \mathrm{mg} / \mathrm{kg}$, respectively [25]).

In this work, the reaction kinetic parameters for the dominant arsenic species, along with the frequency factor and activation energy, were determined through a combination of previous experimental work (through data fitting to establish the vaporization yield model of each arsenic species) [26] and a single-particle combustion model. It is found that the orders of magnitude of the parameters can be obtained with reasonable accuracy allowing for the variations in coal samples and temperature conditions. Combining all of this information allowed us to produce a novel vaporization model for arsenic considering the reaction kinetics of various As species.

\section{Experimental}

For a regular commercial TGA equipment monitoring weight loss, samples are loaded under ambient environment and heated with a low heating rate of $15-20 \mathrm{~K} / \mathrm{min}$, which is not representative of the combustion characteristics in a utility boiler where pulverized coal is fed suddenly into the furnace and heated rapidly (about $10^{3}-10^{4} \mathrm{~K} / \mathrm{s}$ ). In order to study the combustion kinetics of coal sample in the furnace as much as possible, we have developed an isothermal thermogravimetric device innovatively for the mass loss monitoring of the samples 
under constant temperature, see Figure 1. According to the experimental data, the heating rate of coal samples of this device is estimated to be $300-500 \mathrm{~K} / \mathrm{s}$, which is much closer to the actual combustion condition compared to commercial TGA. In addition, the maximum amount allowed in the isothermal thermogravimetric device is $2 \mathrm{~g}$, which ensures the ash collected per run is sufficient for microwave digestion and arsenic detection (minimum requirement $\sim 0.2 \mathrm{~g}$ ), and it also avoids the measure error caused by repeated sampling in a good way. A series of combustion experiments have been conducted with the isothermal thermogravimetric device and the results were internationally recognized [27, 28]. Note that due to the difference in the heat and mass transfer properties between tube furnace and boiler furnace, there is still a gap in the combustion kinetics we have compared to the real condition. Nonetheless, the isothermal thermogravimetric device is one of the most effective tools to measure the kinetics of pulverized coal combustion in power plants.

A wide temperature range of $873-1773 \mathrm{~K}$ was considered during the combustion process. Six coals representing three ranks were combusted isothermally in a horizontal tube furnace $(\Phi 50$ $\mathrm{mm} \times L 120 \mathrm{~mm}$ ) with preset temperatures. A data collection system was connected to monitor the weight loss of the coal sample, as seen in Figure 1. The detailed experimental procedure can be found elsewhere [26].

The coal samples tested are: Baijigou anthracite (BJG), Longyan anthracite (LY), Jinglong bituminous coal (JL), Shijingshan bituminous coal (SJS), Huolinghe lignite (HLH) and Kaiyuan lignite (KY). The ultimate and proximate analyses and arsenic content of coal samples are shown in Table 1. Among them, LY coal is the oldest with a very low volatile content (Volatile $=3.45 \%$ ). $\mathrm{KY}$ is a medium-sulfur coal with the highest arsenic content (As=68.35 $\mu \mathrm{g} / \mathrm{g})$, and the ash content of JL coal is much higher than other coals (Ash=38.58\%). Besides, the two bituminous coals have the similar volatile matter, and it also exists for the two lignites. All coal samples were ground to $100-150 \mu \mathrm{m}$ before use. After combustion, raw coal and solid residuals were digested in a microwave system (SpeedWaveMWS-4, Germany) with nitric acid and hydrofluoric acid to allow their arsenic content to be determined, and the vaporization ratios of arsenic under different conditions were obtained by difference.

Table 1. Coal properties

\begin{tabular}{|c|c|c|c|c|c|c|c|c|c|c|c|}
\hline \multirow{2}{*}{ Coal type } & \multirow{2}{*}{ Name } & \multicolumn{5}{|c|}{ Ultimate analysis, $w_{\mathrm{ad}} / \%$} & \multicolumn{4}{|c|}{ Proximate analysis, $w_{\mathrm{ad}} / \%$} & $\mu \mathrm{g} / \mathrm{g}$ \\
\hline & & $\mathrm{C}$ & $\mathrm{H}$ & $\mathrm{O}$ & $\mathrm{N}$ & $\mathrm{S}$ & Moisture & Volatile & Ash & $\mathrm{FC}$ & Arsenic \\
\hline
\end{tabular}




\begin{tabular}{cccccccccccc} 
Anthracite & BJG & 79.02 & 3.36 & 7.90 & 1.51 & 0.99 & 1.01 & 9.39 & 7.22 & 82.38 & 0.36 \\
Anthracite & LY & 75.62 & 1.28 & 2.35 & 1.26 & 0.6 & 0.54 & 3.45 & 18.89 & 77.12 & 3.19 \\
Bituminous & JL & 44.5 & 3.74 & 12.09 & 0.77 & 0.32 & 1.58 & 22.5 & 38.58 & 37.34 & 0.96 \\
Bituminous & SJS & 60.07 & 4.31 & 9.78 & 0.63 & 0.49 & 1.06 & 22.51 & 24.72 & 51.71 & 4.26 \\
Lignite & HLH & 42.59 & 6.82 & 38.77 & 0.66 & 0.45 & 5.97 & 38.46 & 10.71 & 44.86 & 4.51 \\
Lignite & KY & 44.74 & 5.33 & 32.94 & 1.23 & 1.58 & 4.59 & 39.59 & 14.18 & 41.64 & 68.35 \\
\hline
\end{tabular}

\section{Mathematical models}

\subsection{Vaporized yield model of arsenic}

In order to obtain the reaction kinetics, we must first understand the intermediate process of arsenic vaporization, and to obtain the final vaporization ratio for arsenic corresponding to a certain coal and temperature, the boundary conditions should be specified first. In our previous study [26], isothermal combustion of coals in different ranks was carried out over a wide temperature range of $873-1773 \mathrm{~K}$. Moreover, sequential chemical extraction analysis was performed on coal ashes obtained at these temperatures to study the evolution of arsenic species [29]. Those experimental results were then used here to establish the vaporized yield model of specific arsenic compounds.

In general [12], exchangeable and organic-bound arsenic are easily vaporized during the devolatilization of coal, and arsenic bound to Fe-Mn oxides and pyrite is unstable and tends to vaporize at relatively low temperatures, while arsenates are very stable and decompose only at relatively high temperatures. In this work, arsenic in coal was divided into ion-exchangeable, organic, sulfide and arsenate [26] and here these species were simplified into specific compounds: As-org (representing the organic As compounds), FeAsS (representing As sulfides) and $\mathrm{FeAsO}_{4}$ and $\mathrm{Ca}_{3}\left(\mathrm{AsO}_{4}\right)_{2}$ (representing arsenates, based on the observation of a highly linear correlation between $\mathrm{Ca}$ and Fe content and arsenic in coal ash [26]).

Through the speciation extraction of coal ash at various temperatures, the vaporization ratio change for each arsenic compound was obtained and the data showed an S-shaped growth trend with temperature, which is consistent with our previous findings on arsenic volatilization during co-combustion of high-arsenic lignite blends [14]. In this case, a sigmoidal fitting was applied to the experimental data of these arsenic species to obtain a yield model, as presented in Table 2, where the ratio of vaporized amount $\left(m_{\mathrm{v}}\right)$ to the amount in raw coal $\left(m_{0}\right)$ is denoted as the vaporized yield $(\eta)$. Note that $\mathrm{Ca}_{3}\left(\mathrm{AsO}_{4}\right)_{2}$ does not decompose until $1723 \mathrm{~K}$ and its vaporization model is estimated based on thermodynamic analysis [20]. 
Table 2. Vaporized arsenic yield of various species as a function of temperature

\begin{tabular}{ll}
\hline Arsenic species & Vaporized yield \\
\hline As-org & $\eta_{\mathrm{As}-\mathrm{org}}=\left.\frac{m_{v}}{m_{0}}\right|_{\mathrm{As}-\mathrm{org}}=1-1 /\left(1+\exp \left(\left(T_{g}-873\right) / 20\right)\right)$ \\
$\mathrm{FeAsS}$ & $\eta_{\mathrm{FeAsS}}=\left.\frac{m_{v}}{m_{0}}\right|_{\mathrm{FeAsS}}=1-1 /\left(1+\exp \left(\left(T_{g}-1167\right) / 132\right)\right)$ \\
$\mathrm{FeAsO}_{4}$ & $\eta_{\mathrm{FeAsO}_{4}}=\left.\frac{m_{v}}{m_{0}}\right|_{\mathrm{FeAsO}_{4}}=1-1 /\left(1+\exp \left(\left(T_{g}-1600\right) / 45\right)\right)$ \\
$\mathrm{Ca}_{3}\left(\mathrm{AsO}_{4}\right)_{2}$ & $\eta_{\mathrm{Ca}_{3}\left(\mathrm{AsO}_{4}\right)_{2}}=\left.\frac{m_{v}}{m_{0}}\right|_{\mathrm{Ca}_{3}\left(\mathrm{AsO}_{4}\right)_{2}}=1-1 /\left(1+\exp \left(\left(T_{g}-2200\right) / 57\right)\right)$ \\
\hline
\end{tabular}

With this vaporized yield model, the total vaporization ratio of arsenic in coal was predicted and compared to the results from our previous experiments [26], which represent twenty-four cases including six coals of three coal ranks under various temperatures, as shown in Figure 2.

It is found in Figure 2 that the R-squared value of the linear fit between experimental and predicted data is 0.9664 , showing a high fitting degree in spite of the variation in coals as well as combustion temperatures, which offers an excellent indication of the reliability of this vaporized yield model and provides the basis for determination of the reaction kinetics of arsenic in the sections below.

\subsection{Single-particle coal combustion model}

The single-particle model provides the internal description to account for intraparticle heatand mass-transfer resistances, and assumes an isotropic, spherical and porous particle, burning in a free, isothermal environment with initial particle temperature $T_{0}=298 \mathrm{~K}$. The accuracy depends upon the number, $N$, of discretization shells (see Figure 3; in this work, $N$ was set to 6 with each shell having the same thickness, $\left.d_{\mathrm{p}} / 2 N\right)$. This feature becomes fundamental for the analysis of pyrolysis, char combustion, gas-solid chemical reactions as well as determining the vaporization kinetics of arsenic. Heat conduction along the radius of the particle is calculated by solving the heat diffusion equation. Similarly, internal gradients of gas-phase species are calculated by solving the corresponding continuity equations. The evolution of porosity of each shell and the whole particle are taken into account.

(1) Mass and energy balances

The mass (solid and gas phase) and energy balances in each particle shell are: 


$$
\begin{aligned}
& \frac{\partial m_{s}}{\partial t}=M_{s} \times V_{g s} \sum R_{i} \\
& \frac{\partial C_{g s}}{\partial t}=\frac{D_{e}}{r^{2}} \frac{\partial}{\partial r}\left(r^{2} \frac{\partial C_{g s}}{\partial r}\right)+\sum R_{i} \\
& \frac{\partial\left(c_{p s} \rho_{s} T_{s}\right)}{\partial t}=-D_{e} \frac{1}{r^{2}} \frac{\partial}{\partial r}\left(r^{2} c_{p s} T_{s} \frac{\partial \dot{m}_{g s}}{\partial r}\right)+\lambda_{e} \frac{1}{r^{2}} \frac{\partial}{\partial r}\left(r^{2} \frac{\partial T_{s}}{\partial r}\right)+\sum R_{i} \Delta H_{i}
\end{aligned}
$$

At the external surface of a single particle, the flux contributions inside the particle are replaced by the flux exchanged with the bulk phase. Stefan flow was taken into account and the corresponding energy balance at the particle surface is:

$$
\begin{aligned}
\left.\frac{\partial\left(c_{p s} \rho_{s} T_{s}\right)}{\partial t}\right|_{r=d_{p} / 2} & =\left(\frac{1}{\frac{1}{k_{m}}+\frac{\delta r}{D_{e}}}\right) c_{p s} T_{N}\left[\dot{m}_{g N}-\dot{m}_{\text {bulk }}\right]+\left(\frac{1}{\frac{1}{h}+\frac{\delta r}{\lambda_{e}}}\right)\left[T_{N}-T_{\text {bulk }}\right]+ \\
& +\sigma \varepsilon_{\text {rad }}\left[T_{N}^{4}-T_{\text {wall }}^{4}\right]+\sum R_{i} \Delta H_{i}
\end{aligned}
$$

The right side of Eq.(4) consists of four terms. The first term represents the mass transfer and diffusion due to mass concentration difference between gas on the particle surface and gas in the bulk considering the Stefan flow. The second term represents heat conduction and heat convection due to the temperature difference between the particle surface and bulk gas. The third term is the radiation term. At the external surface of a single particle, radiation heat transfer occurs between the particle surface and environment wall. The last term is the internal heat source term, which is the sum of the heat release of chemical reactions on the particle surface.

The mass and energy balances of gas in the boundary layer are:

$$
\begin{aligned}
& \frac{\partial C_{g g}}{\partial t}=\frac{D_{e}}{r^{2}} \frac{\partial}{\partial r}\left(r^{2} \frac{\partial C_{g g}}{\partial r}\right)+\sum R_{i} \\
& \frac{\partial\left(c_{p g} \rho_{g} T_{g}\right)}{\partial t}=-D_{b u l k} \frac{1}{r^{2}} \frac{\partial}{\partial r}\left(r^{2} c_{p g} T_{g} \frac{\partial \dot{m}_{g g}}{\partial r}\right)+\lambda_{b u l k} \frac{1}{r^{2}} \frac{\partial}{\partial r}\left(r^{2} \frac{\partial T_{g}}{\partial r}\right)+\sum R_{i} \Delta H_{i}
\end{aligned}
$$

where $T_{s}, T_{N}, T_{g}, T_{b u l k}$ and $T_{\text {wall }}$ are temperatures inside the particle, at the external surface of the particle, in the boundary layer, of bulk gas and of environmental wall, respectively; $\rho_{s}$ and $\rho_{g}$ are the gas density inside the particle and in the boundary layer, respectively; $c_{p s}$ and $c_{p g}$ are the specific heat capacity of gas inside the particle and in the boundary layer, respectively; $m_{s}$ and $M_{s}$ are the mass and molecular weight of solid components inside the particle, respectively; 
$V_{g s}$ is the gas volume in the $j$-th particle shell; $R_{i}$ and $\Delta H_{i}$ are the rate and heat release of reaction $i$, respectively; $k_{m}$ and $h$ are the mass transfer and surface heat convection coefficients, respectively; $C_{g s}$ and $C_{g g}$ are the molar concentration of gas inside the particle and in the boundary layer, respectively; $\dot{m}_{g s}, \dot{m}_{g N}, \dot{m}_{g g}$ and $\dot{m}_{b u l k}$ are the mass concentration of gas inside the particle, at the external surface of the particle, in the boundary layer, and of bulk gas, respectively; $D_{e}$ and $\lambda_{e}$ are the effective diffusion and heat conduction coefficients of gas inside the particle, respectively; $D_{b u l k}$ and $\lambda_{b u l k}$ are the molecular diffusion and heat conduction coefficients of bulk gas, respectively; and $\delta r$ is the boundary layer thickness. Based on the literature $[30,31]$, the thickness of the boundary layer was fixed to be equal to the particle diameter. $\sigma$ is the Stefan-Boltzmann constant; $\varepsilon_{r a d}$ is the emissivity of the coal particle and is assumed as $0.8[32,33]$.

Porosity $\left(\varepsilon_{j}\right)$ increases linearly with the char conversion ratio of the $j$-th particle shell $\left(X_{j}\right)$. The initial and maximum porosity of each particle shell $\left(\varepsilon_{j}^{0}\right.$ and $\left.\varepsilon_{j}^{\max }\right)$ are set to 0.25 and 0.8 , respectively $[34,35]$.

$$
\varepsilon_{j}=\varepsilon_{j}^{0}+X_{j}\left(\varepsilon_{j}^{\max }-\varepsilon_{j}^{0}\right)
$$

(2) Pyrolysis model (devolatilization)

A universal Fu-Zhang model [36] was applied to calculate the devolatilization ratio of volatile matter with time, while the devolatilization rate is described as below:

$$
R_{V o l}=\frac{d V}{d t}=\left(V^{0}-V\right) k_{0} \exp \left(-E_{0} / R T\right)
$$

where $V$ is the mass fraction of volatile matter in a single coal particle with initial value being $V^{0}$. $R$ is the gas constant; $k_{0}=1.3583 \times \exp (0.0114 \times T)$ and $E_{0}=14555 \times \exp (0.0014 \times T)$ are the only parameters that are temperature-related [36].

(3) Random pore model (char combustion)

The specific surface area of char particle $(S)$ is calculated using the random pore model of Bhatia and Perlmutter [37]:

$$
\frac{S}{S_{0}}=(1-X) \sqrt{1-\psi \ln (1-X)}
$$

where $S_{0}$ is the specific surface area at zero carbon burn-off for devolatilized char; and $\psi$ is the 
dimensionless parameter known as pore parameter, whose value depends on the nature of the coal char, $\psi=4 \pi L_{0}\left(1-\varepsilon_{0}\right) / S_{0}^{2} . L_{0}$ is the total pore length per unit volume.

\subsection{Chemical reactions}

\subsubsection{Homogeneous reactions}

Gas products from the devolatilization process are mainly $\mathrm{CH}_{4}, \mathrm{H}_{2}, \mathrm{CO}, \mathrm{CO}_{2}, \mathrm{H}_{2} \mathrm{O}(\mathrm{g})$ and tar. The amounts of these gases were calculated using the empirical equations proposed by Gregory and Littlejohn [38]. In addition, organic sulfur (simplified as $\mathrm{H}_{2} \mathrm{~S}$ ) and organic arsenic (As-org) were also considered to vaporize in this process. The dominant homogeneous reactions and their respective kinetics are shown below in Table 3. Note the unit of frequency factor changes with the reaction order and type.

$$
\begin{gathered}
\mathrm{CH}_{4}+3 / 2 \mathrm{O}_{2}=\mathrm{CO}+2 \mathrm{H}_{2} \mathrm{O}(\mathrm{g}) \\
\mathrm{H}_{2}+0.5 \mathrm{O}_{2}=\mathrm{H}_{2} \mathrm{O}(\mathrm{g}) \\
\mathrm{CO}+1 / 2 \mathrm{O}_{2}=\mathrm{CO}_{2} \\
\mathrm{Tar}+\mathrm{O}_{2}=\mathrm{CO}_{2}+\mathrm{H}_{2} \mathrm{O}(\mathrm{g}) \\
\mathrm{H}_{2} \mathrm{~S}+3 / 2 \mathrm{O}_{2}=\mathrm{SO}_{2}+\mathrm{H}_{2} \mathrm{O}(\mathrm{g}) \\
\text { As-org }+\mathrm{O}_{2}=\mathrm{As}_{2} \mathrm{O}_{3}(\mathrm{~g})
\end{gathered}
$$

\begin{tabular}{|c|c|c|c|c|}
\hline No. & Reaction rate- $R_{\mathrm{i}}, \mathrm{mol} /\left(\mathrm{m}^{3} \cdot \mathrm{s}\right)$ & Frequency factor- $k_{\mathrm{i}}$ & $\begin{array}{l}\text { Activation } \\
\text { energy- } E_{\mathrm{i}}, \mathrm{kJ} / \mathrm{mol}\end{array}$ & Reference \\
\hline $\mathrm{R} 1$ & $R_{1}=k_{1} \exp \left(E_{1} / R T\right) C_{C_{H_{4}}}^{0.7} C_{O_{2}}^{0.8}$ & $1.585 \times 10^{10},\left(\mathrm{~m}^{3} / \mathrm{mol}\right)^{0.5} \cdot(1 / \mathrm{s})$ & 200.8 & [39] \\
\hline $\mathrm{R} 2$ & $R_{2}=k_{2} \exp \left(-E_{2} / R T\right) C_{H_{2}}^{1.5} C_{O_{2}}$ & $1.63 \times 10^{9},\left(\mathrm{~m}^{3} / \mathrm{mol}\right)^{1.5} \cdot(1 / \mathrm{s})$ & 28.4 & [39] \\
\hline $\mathrm{R} 3$ & $\begin{array}{c}R_{3}=k_{3} \exp \left(-E_{3} / R T\right) \varphi C_{C O}\left(C_{O_{2}} / 2\right)^{0.25} C_{H_{2} O}^{0.5} \\
\varphi=7.98 \times 10^{12} \exp \left(-2.48 \times C_{C O} / C_{O_{2}}\right)\end{array}$ & $2.23 \times 10^{12},\left(\mathrm{~m}^{3} / \mathrm{mol}\right)^{0.75} \cdot(1 / \mathrm{s})$ & 20.1 & [39] \\
\hline $\mathrm{R} 4$ & $R_{4}=k_{4} \exp \left(-E_{4} / R T\right) C_{T a r} C_{O_{2}}$ & $3.8 \times 10^{4}, \mathrm{~m}^{3} /(\mathrm{mol} \cdot \mathrm{s})$ & 55.5 & [39] \\
\hline R5 & $R_{5}=k_{5} \exp \left(-E_{5} / R T\right) C_{H_{2} S} C_{O_{2}}^{0.75}$ & $2.1 \times 10^{10},\left(\mathrm{~m}^{3} / \mathrm{mol}\right)^{0.75} \cdot(1 / \mathrm{s})$ & 157.1 & {$[40]$} \\
\hline R6 & $R_{6}=k_{6} \exp \left(-E_{6} / R T\right) C_{A s-o r g} C_{O_{2}}$ & $\mathrm{TBD}, \mathrm{m}^{3} /(\mathrm{mol} \cdot \mathrm{s})$ & TBD & \\
\hline
\end{tabular}

Table 3. Chemical kinetics of homogeneous reactions

TBD: to be determined.

\subsubsection{Heterogeneous reactions}

Heterogeneous reactions include char oxidation, char gasification, pyrite oxidation, sulfation, sulfide-bound arsenic oxidation and arsenate decomposition. Though the emission of $\mathrm{SO}_{2}$ is not a goal of this work, pyrite oxidation reactions were included due to the high correlation between arsenic and pyrite in coal [21]. In this work, two pyrites, $\mathrm{FeS}_{2}$ and $\mathrm{Fe}_{1.25} \mathrm{~S}$ were considered [41]. 
The competition between $\mathrm{SO}_{2}$ and $\mathrm{As}_{2} \mathrm{O}_{3}$ on metal oxides $(\mathrm{Ca} / \mathrm{Fe}$-based) adsorption in the vaporization process was ignored due to high-temperature decomposition of arsenates (R14, R15, see Table 3) in the boiler [20]. The relevant dominant reactions are listed below, and their chemical kinetics can be found in Table 4. The reaction order of R13 was assumed equal to 1 . Note the unit of frequency factor changes with the reaction order and type.

$$
\begin{gathered}
2(\alpha+\beta) /(\alpha+2 \beta) C_{\text {char }}+O_{2}=2 \alpha /(\alpha+2 \beta) C O+2 \beta /(\alpha+2 \beta) C O_{2} \\
\mathrm{C}_{\text {char }}+\mathrm{CO}_{2}=2 \mathrm{CO} \\
3 \mathrm{FeS}_{2}+8 \mathrm{O}_{2}=\mathrm{Fe}_{3} \mathrm{O}_{4}+6 \mathrm{SO}_{2}(\mathrm{~g}) \\
\mathrm{Fe}_{1.25} \mathrm{~S}+5.5 / 3 \mathrm{O}_{2}=1.25 / 3 \mathrm{Fe}_{3} \mathrm{O}_{4}+\mathrm{SO}_{2}(\mathrm{~g}) \\
\mathrm{Fe}_{3} \mathrm{O}_{4}+0.25 \mathrm{O}_{2}=1.5 \mathrm{Fe}_{2} \mathrm{O}_{3} \\
\mathrm{CaO}+\mathrm{SO}_{2}(\mathrm{~g})+1 / 2 \mathrm{O}_{2}(\mathrm{~g})=\mathrm{CaSO}_{4} \\
3 \mathrm{FeAsS}+7.25 \mathrm{O}_{2}=\mathrm{Fe}_{3} \mathrm{O}_{4}+3 / 2 \mathrm{As}_{2} \mathrm{O}_{3}(\mathrm{~g})+3 \mathrm{SO}_{2} \\
\mathrm{FeAsO}=1 / 3 \mathrm{Fe}_{3} \mathrm{O}_{4}+1 / 2 \mathrm{As}_{2} \mathrm{O}_{3}(\mathrm{~g})+7 / 12 \mathrm{O}_{2} \\
\mathrm{Ca}_{3}\left(\mathrm{AsO}_{4}\right)_{2}=3 \mathrm{CaO}+\mathrm{As}_{2} \mathrm{O}_{3}(\mathrm{~g})+\mathrm{O}_{2}
\end{gathered}
$$

\begin{tabular}{|c|c|c|c|c|}
\hline No. & Reaction rate of solid reactant- $R_{\mathrm{i}}, \mathrm{mol} / \mathrm{s}$ & Frequency factor- $k_{\mathrm{i}}$ & $\begin{array}{l}\text { Activation energy- } \\
E_{\mathrm{i}}, \mathrm{kJ} / \mathrm{mol}\end{array}$ & Reference \\
\hline R7 & $\begin{array}{l}R_{7}=k_{7} \times T \times \exp \left(-E_{7} / R T\right) \times S \times C_{O_{2}} \\
\text { molar ratio of } \mathrm{CO} / \mathrm{CO}_{2}: \\
\quad \alpha / \beta=2400 \exp (-51830 / R T)\end{array}$ & $250, \mathrm{~m}^{4} /(\mathrm{K} \cdot \mathrm{s})$ & 158.0 & [42] \\
\hline $\mathrm{R} 8$ & $R_{8}=k_{8} \exp \left(-E_{9} / R T\right) \times S \times C_{\mathrm{CO}_{2}}$ & $4346, \mathrm{~m}^{4} / \mathrm{s}$ & 248.1 & [39] \\
\hline R9 & $R_{9}=k_{9} \exp \left(-E_{9} / R T\right) \times n_{\mathrm{FeS}_{2}} \times P_{\mathrm{O}_{2}}$ & $1.7 \times 10^{-2}, 1 /(\mathrm{Pa} \cdot \mathrm{s})$ & 87.9 & [41] \\
\hline R10 & $R_{10}=k_{10} \exp \left(-E_{10} / R T\right) \times n_{F e_{1,25} S} \times P_{O_{2}}$ & $2.1 \times 10^{-5}, 1 /(\mathrm{Pa} \cdot \mathrm{s})$ & 92.5 & [41] \\
\hline R11 & $R_{11}=k_{11} \exp \left(-E_{11} / R T\right) \times n_{\mathrm{Fe}_{3} \mathrm{O}_{4}} \times P_{\mathrm{O}_{2}}$ & $5.3,1 /(\mathrm{Pa} \cdot \mathrm{s})$ & 100 & [41] \\
\hline $\mathrm{R} 12$ & $R_{12}=k_{12} \exp \left(-E_{12} / R T\right) \times n_{\mathrm{CaO}} \times P_{O_{2}}$ & $2.65,1 /(\mathrm{Pa} \cdot \mathrm{s})$ & 36.6 & [43] \\
\hline R13 & $R_{13}=k_{13} \exp \left(-E_{13} / R T\right) \times n_{F e A s S} \times P_{O_{2}}$ & TBD, $1 /(\mathrm{Pa} \cdot \mathrm{s})$ & TBD & \\
\hline $\mathrm{R} 14$ & $R_{14}=k_{14} \exp \left(-E_{14} / R T\right) \times n_{\mathrm{FeASO}_{4}}$ & $\mathrm{TBD}, 1 / \mathrm{s}$ & TBD & \\
\hline R15 & $R_{15}=k_{15} \exp \left(-E_{15} / R T\right) \times n_{\left(a_{3}\left(\mathrm{AsO}_{4}\right)_{2}\right.}$ & $\mathrm{TBD}, 1 / \mathrm{s}$ & TBD & \\
\hline
\end{tabular}

Table 4. Chemical kinetics of heterogeneous reactions

TBD: to be determined.

Among these reactions, the kinetic parameters for arsenic-related reactions R6, R13, R14 and R15 are unknown and are determined in the "Results and discussion" section below.

\section{Computer model flow diagram}

A computer program was developed to determine the kinetics of arsenic-related reactions (R6 
and R13-R15) based on the single-particle coal combustion model combined with the vaporized yield model for arsenic. The flow diagram for the computer model developed is shown in Figure 4. The inputs to this model can be split into three groups: (1) coal properties, arsenic and sulfur compounds in coal; (2) single-particle division parameters; and (3) gas compositions, bulk gas temperature, with the time step considered.

In this model, the proportions of specific arsenic species in coal are key inputs. Due to the fact that the extraction experiments could not separate $\mathrm{FeAsO}_{4}$ from arsenates, the ratio of $\mathrm{FeAsO}_{4}$ to arsenate is set to 0.2 for anthracite and 0.8 for bituminous or lignite coal based on the experimental vaporization ratio of arsenic under high temperature (1773K) [26]. For JL coal with $\mathrm{Al}_{2} \mathrm{O}_{3}$ levels of up to $52.75 \%$ in the ash composition [26], $\mathrm{AlAsO}_{4}$ is thought to be the dominant arsenate and the ratio of $\mathrm{FeAsO}_{4}$ to arsenate in JL coal is set to 0.02. Based on the assumptions above, input arsenic compounds and proportions to total arsenic are listed in Table 5.

Table 5. Arsenic compounds and proportions to total arsenic as input

\begin{tabular}{lllllll}
\hline \multirow{2}{*}{ Arsenic Species } & \multicolumn{6}{c}{ Proportion of arsenic species to total arsenic mass, \% } \\
\cline { 2 - 6 } & BJG & LY & JL & SJS & HLH & KY \\
\hline As-organic & 0 & 0 & 10 & 31 & 14 & 11 \\
FeAsS & 49 & 43 & 42 & 42 & 69 & 88 \\
$\mathrm{FeAsO}_{4}$ & 10.2 & 11.4 & 0.96 & 21.6 & 13.6 & 0.8 \\
$\mathrm{Ca}_{3}\left(\mathrm{AsO}_{4}\right)_{2}$ & 40.8 & 45.6 & 47.04 & 5.4 & 3.4 & 0.2 \\
\hline
\end{tabular}

The diameter of the single coal particle in this model is fixed at $100 \mu \mathrm{m}$, which is comparable to the experimental coal sizes. Particle densities for anthracite, bituminous and lignite coals are 1600,1300 and $1200 \mathrm{~kg} / \mathrm{m}^{3}$, respectively [44, 45]. Initial gas composition is $21 \mathrm{O}_{2} / 79 \mathrm{~N}_{2}$ (air composition) for all simulations. Here the time step chosen is $10^{-6} \mathrm{~s}$. At each time step, the carbon mass, gas concentration including arsenic and sulfur and arsenic conversion ratio in each spherical shell were first computed. This gave the degree of volatile and char combustion, chemical reactions and gas diffusion, output shell temperature, shell gas composition and concentration, which in turn provided the shell arsenic conversion ratio for the next time step.

\section{Results and discussion}

\subsection{Single coal particle combustion characteristics}

Taking the example of KY coal, a typical high-arsenic coal, the combustion characteristics of a single coal particle at different temperature conditions are shown in Figure 5, where (a1) - (a4) 
are for KY coal at $1173 \mathrm{~K}$, and (b1) - (b4) are for KY coal at $1773 \mathrm{~K}$. The change of temperature in the solid phase and gas phase, the dominant gas $\left(\mathrm{O}_{2}, \mathrm{CO}\right.$ and $\left.\mathrm{CO}_{2}\right)$ concentrations inside the pores of coal as well as in the boundary layer are represented.

As the bulk gas temperature increases from $1173 \mathrm{~K}$ to $1773 \mathrm{~K}$, it is clear that one sees a shorter burnout time for the single KY coal particle ((a1) $140 \mathrm{~ms} v \mathrm{~s}$. (b1) $40 \mathrm{~ms}$ ), faster $\mathrm{O}_{2}$ consumption $\left(\mathrm{O}_{2}\right.$ ratio range in mixed gas: (a2) 0.16-0.21 vs. (b2) 0.01-0.21), more $\mathrm{CO}$ generation in the combustion process (peak $\mathrm{CO}$ ratio in mixed gas: (a3) 0.07 vs. (b3) 0.3) and more $\mathrm{CO}_{2}$ generation in combustion process ((a4) $0.014 v s$. (b4) 0.12). These changes are due to the more intensive devolatilization and char combustion behavior under the higher temperature condition, which causes the $\mathrm{O}_{2}$ concentration to decrease rapidly and thus produces a higher $\mathrm{CO}_{2}$ release peak, while a lack of $\mathrm{O}_{2}$ on the char surface results in more $\mathrm{CO}$ generation and thus a higher $\mathrm{CO}$ release peak. These modeling results are consistent with the modeling work of other researchers studying single coal particle combustion [34, 46-48], suggesting the reliability and applicability of the single-particle coal combustion model to provide the necessary information to determine the kinetic parameters for arsenic needed here.

\subsection{Determination of arsenic-related kinetic parameters}

The determination of the kinetics of arsenic-related reactions should be based on the following: (1) the boundary condition: the vaporized yield of each arsenic compound at specific temperature, which provides the initial and final states before determining the intermediate kinetic process; (2) according to the thermal stabilities of various arsenic species, the activation energies $\left(E_{0}\right)$ in increasing order are: As-org $<\mathrm{FeAsS}<\mathrm{FeAsO}_{4}<\mathrm{Ca}_{3}\left(\mathrm{AsO}_{4}\right)_{2}$; (3) organic arsenic (As-org) vaporizes and must be part of the same mass loss peak as the volatile matter of the coal particle. When devolatilization completes, the vaporization of As-org stops. It is reasonable to assume that R6 (oxidation reaction of As-org) has the same activation energy as R4 (Tar vaporization), that is $E_{0_{-} \mathrm{R} 6}=E_{0 \_} \mathrm{R} 4 \approx 55 \mathrm{~kJ} / \mathrm{mol}$; (4) FeAsS vaporizes in the former stage of coal combustion due to its low thermal stability. Since arsenic substitutes for a sulfur atom in $\mathrm{FeS}_{2}$ to form FeAsS, the two compounds are assumed to have similar activation energy values, thus a reasonable assumption $E_{0 \_} \mathrm{R}_{3}=90 \mathrm{~kJ} / \mathrm{mol}$ was chosen; and (5) $\mathrm{FeAsO}_{4}$ and $\mathrm{Ca}_{3}\left(\mathrm{AsO}_{4}\right)_{2}$ decompose during the char combustion stage. When char burnout occurs, the arsenate decomposition process must be completed as well.

Note that the kinetic parameters of reactions R6, R13, R14 and R15 should meet all of the 
limitations above, and account for the mass loss peaks of volatiles and char of the single particle for all the tested coals and tested temperatures. In addition, the vaporization zones of different arsenic compounds were estimated from sequential chemical extraction results [29]. The peak vaporization and $100 \%$ vaporization temperature are: $873 \mathrm{~K}$ and $1073 \mathrm{~K}$ for As-org; and $1167 \mathrm{~K}$ and $1473 \mathrm{~K}$ for FeAsS. For the two arsenates $\left(\mathrm{FeAsO}_{4}\right.$ and $\left.\mathrm{Ca}_{3}\left(\mathrm{AsO}_{4}\right)_{2}\right)$, the temperature data were estimated through thermodynamic analysis, given their relatively high thermal stabilities, and the details of these processes are discussed later.

\subsubsection{Organic arsenic (As-org)}

With a reasonable assumed activation energy of $\mathrm{R} 6\left(E_{0_{-} \mathrm{R} 6}=55 \mathrm{~kJ} / \mathrm{mol}\right)$, the determination process of the frequency factor $\left(k_{0 \_} \mathrm{R} 6\right)$ for organic arsenic oxidation is shown in Figure 6, taking KY coal as an example with three subfigures (a) at $873 \mathrm{~K}$, (b) at $1173 \mathrm{~K}$ and (c) at $1773 \mathrm{~K}$. Note the data in Figure 6 are shell-average-based. Since organic arsenic (As-org) vaporizes with the devolatilization process, the mass loss ratio and mass loss rate of volatile matter during the single coal particle combustion were computed as shown in Figure 6(a1), (b1) and (c1). Figure 6(a2), (b2) and (c2) show the temporal change of $\mathrm{As}_{2} \mathrm{O}_{3}(\mathrm{~g})$ concentration in mixed gas (unit: ppb v/v) caused by As-org oxidation. Figure 6(a3), (b3) and (c3) show the conversion ratio of As-org.

The vaporization curves of $\mathrm{As}_{2} \mathrm{O}_{3}(\mathrm{~g})$ obtained with various frequency factors $\left(1 \times 10^{5}-1 \times 10^{10}\right)$ were compared to the mass loss rates of volatile matter over a wide temperature range (873$1773 \mathrm{~K})$. At $873 \mathrm{~K}$ when $k_{0 \_\mathrm{R} 6}=1 \times 10^{5}$ or $1 \times 10^{6} 1 / \mathrm{s}$, the $\mathrm{As}_{2} \mathrm{O}_{3}(\mathrm{~g})$ concentration peak occurs after the mass loss peak of volatile matter as seen in Figure 6(a). Based on the simultaneous vaporization assumption for organic arsenic and volatile matter, the range of the order of magnitude of $k_{0}{ }_{\text {R6 } 6}$ was then narrowed to $1 \times 10^{7}-1 \times 10^{10}$. As the temperature increased to $1173 \mathrm{~K}$ (Figure $6(\mathrm{~b})$ ), $1 \times 10^{10}$ was no longer used and this range was reduced to $1 \times 10^{7}-1 \times 10^{9}$ and, finally reduced to $1 \times 10^{8}-1 \times 10^{9}$ at $1773 \mathrm{~K}$. The two frequency factors, $1 \times 10^{8}$ and $1 \times 10^{9}$, were validated by other coal combustion conditions using the same determination process in Figure 6. To keep this manuscript reasonably brief, the validations for other coal samples are not shown here.

The wide range of the determined frequency factors suggests that the effective collision times are almost unchanged when the frequency factor increases from $1 \times 10^{8}$ to $1 \times 10^{9}$, indicating that the collision times may have reached the upper limit at $1 \times 10^{8}$; thus, further increase of the frequency factor has little effect on the released $\mathrm{As}_{2} \mathrm{O}_{3}(\mathrm{~g})$ amount. However, it should be noted that when this number becomes much higher $\left(1 \times 10^{10}\right)$, the $\mathrm{As}_{2} \mathrm{O}_{3}(\mathrm{~g})$ concentration curve changes 
severely at $1173 \mathrm{~K}$ (see Figure $6(\mathrm{~b} 2)$ ). The main reason is that from $873 \mathrm{~K}$ to $1173 \mathrm{~K}$, the reaction rate of R6 increased exponentially, which made the consumption amount of As-org even larger than the vaporized amount of As-org at some given time. Thus, no residual As-org was left and the $\mathrm{As}_{2} \mathrm{O}_{3}(\mathrm{~g})$ concentration decreased sharply to zero.

Overall, the kinetic parameters of R6 (organic arsenic oxidation) were determined to be $k_{0}$ R6 $=1 \times 10^{8}-1 \times 10^{9} 1 / \mathrm{s}$ and $E_{0} \_\mathrm{R} 6=55 \mathrm{~kJ} / \mathrm{mol}$.

\subsubsection{Sulfide-bound arsenic (FeAsS)}

With a reasonable assumed activation energy for R13 $\left(E_{0 \_\mathrm{R} 13}=90 \mathrm{~kJ} / \mathrm{mol}\right)$, the determination process of the frequency factor ( $k_{0} \_$R13) on FeAsS oxidation is shown in Figure 7, taking KY coal as an example with three subfigures (a) at $1173 \mathrm{~K}$, (b) at $1373 \mathrm{~K}$ and (c) at $1773 \mathrm{~K}$. Note the data in Figure 7 are shell-average-based. Since sulfide-bound arsenic (FeAsS) vaporizes along with coal combustibles, the mass loss ratio and mass loss rate of (volatile + char) during single coal particle combustion were computed as shown in Figure 7(a1), (b1) and (c1). Figure 7(a2), (b2) and (c2) show the temporal change of $\mathrm{As}_{2} \mathrm{O}_{3}(\mathrm{~g})$ concentration in mixed gas (unit: ppb v/v) caused by FeAsS oxidation. Figure 7(a3), (b3) and (c3) show the conversion ratio of FeAsS.

From Figure 7(a1), (b1) and (c1) it can be seen that two mass loss peaks occur during KY coal combustion. From comparison with the separate mass loss curves for volatiles and char, it is found that volatile matter and part of the char contributed to the first peak and the residual char combustion contributed to the second peak. This oxidation delay phenomenon for coal char is mainly due to rapid consumption of oxygen taking place in the ignition and initial combustion stage, which caused a depletion of the oxygen in the inner spherical shells of the coal particle.

According to the relatively low thermal stability of $\mathrm{FeAsS}$, the $\mathrm{As}_{2} \mathrm{O}_{3}(\mathrm{~g})$ concentration generated by FeAsS oxidation was compared to the first mass loss peak of coal combustibles with various frequency factors $\left(1 \times 10^{2}-1 \times 10^{4}\right)$ under a wide temperature range $(1173 \mathrm{~K}$ to $1773 \mathrm{~K})$. Following this approach, $1 \times 10^{2}$ and $1 \times 10^{4}$ were excluded due to the fact that the $\mathrm{As}_{2} \mathrm{O}_{3}(\mathrm{~g})$ releasing rate was either too fast or too slow at $1173 \mathrm{~K}$ (Figure $7(\mathrm{a})$ ). $k_{0} \_\mathrm{R} 13=5 \times 10^{3} 1 /(\mathrm{Pa} \cdot \mathrm{s}$ ) was excluded subsequently in order to match the combustion characteristics at $1373 \mathrm{~K}$ (Figure 7(b)). As a result, $1 \times 10^{3}$ and $2 \times 10^{3}$ were left and applied at $1773 \mathrm{~K}$ (Figure $7(\mathrm{c})$ ). It can be seen in Figure $7(\mathrm{c} 2)$ that when the frequency factor was changed from $1 \times 10^{3}$ to $2 \times 10^{3}$, significant redistribution was observed for the two $\mathrm{As}_{2} \mathrm{O}_{3}(\mathrm{~g})$ peaks. The ratio of the first peak height to the second peak height is larger than 1 when $k_{0} \_\mathrm{R} 13=2 \times 10^{3} 1 /(\mathrm{Pa} \cdot \mathrm{s})$ while less than 1 when 
$k_{0 \_\mathrm{R} 13}=1 \times 10^{3} 1 /(\mathrm{Pa} \cdot \mathrm{s})$. This suggests that with a higher frequency factor, a larger proportion of FeAsS would vaporize rapidly. Considering the activity of FeAsS in the ignition and initial combustion stage, $k_{0} \_\mathrm{R} 13=1 \times 10^{3} 1 /(\mathrm{Pa} \cdot \mathrm{s})$ was excluded and the value of $k_{0} \_\mathrm{R} 13$ was deduced to be $2 \times 10^{3}$. This number was subsequently validated by other coal samples and temperature conditions. Overall, the kinetic parameters of R13 (FeAsS oxidation) are determined to be $k_{0}{ }^{\mathrm{R} 13}$ $=2 \times 10^{3} 1 /(\mathrm{Pa} \cdot \mathrm{s})$ and $E_{0 \_\mathrm{R} 13}=90 \mathrm{~kJ} / \mathrm{mol}$.

Comparing Figure 7 (c2) with Figure 7 (a2) and (b2), it is found that one $\mathrm{As}_{2} \mathrm{O}_{3}(\mathrm{~g})$ concentration peak occurred at $1173 \mathrm{~K}$ or $1373 \mathrm{~K}$ while two $\mathrm{As}_{2} \mathrm{O}_{3}(\mathrm{~g})$ concentration peaks occurred at $1773 \mathrm{~K}$. The $\mathrm{As}_{2} \mathrm{O}_{3}(\mathrm{~g})$ concentration did not produce bimodal peaks at $<1373 \mathrm{~K}$ as did that of coal mass loss. This phenomenon can be explained by the kinetics difference of char oxidation (R7) and FeAsS oxidation (R13). Compared to R7, R13 occurs more readily due to lower activation energy. At $<1373 \mathrm{~K}$, the effect of activation energy was dominant, which allowed enough oxygen to react with FeAsS without any delay and, as such, only one $\mathrm{As}_{2} \mathrm{O}_{3}(\mathrm{~g})$ peak was obtained. When the temperature was high $(1773 \mathrm{~K})$, the effect of activation energy was weakened. Instead, higher oxygen consumption led to a lack of oxygen to react with FeAsS, and thus the oxidation of FeAsS was partly delayed and one more $\mathrm{As}_{2} \mathrm{O}_{3}(\mathrm{~g})$ peak was observed. Due to the competition for oxygen between R7 and R13, it is found in Figure 7(c) that the second $\mathrm{As}_{2} \mathrm{O}_{3}(\mathrm{~g})$ peak occurred after the second mass loss peak of coal combustibles.

\subsubsection{Arsenates}

Unlike R6 or R13 with only one variable to be determined, the activation energy and the frequency factor of R14 (FeAsS decomposition) and $\mathrm{R} 15\left(\mathrm{Ca}_{3}\left(\mathrm{AsO}_{4}\right)_{2}\right.$ decomposition) are both unknown. In this case, several combinations of the two variables were computed, as seen in Figure 8 and Figure 9.

\subsubsection{1 $\mathrm{FeAsO}_{4}$}

Taking KY coal as an example, the determination process for the frequency factor $\left(k_{0} \_\right.$R14 $)$ and activation energy ( $\left.E_{0}{ }_{-} \mathrm{R} 14\right)$ with regard to $\mathrm{FeAsO}_{4}$ decomposition is shown in Figure 8, with two subfigures (a) at $1773 \mathrm{~K}$ (complete decomposition) and (b) at $1373 \mathrm{~K}$ (partial decomposition). Since $\mathrm{FeAsO}_{4}$ decomposes along with the char combustion process, the mass loss ratio and mass loss rate of char during single coal particle combustion were computed as shown in Figure 8(a1) and (b1). Figure 8(a2) and (b2) show the temporal change of $\mathrm{As}_{2} \mathrm{O}_{3}(\mathrm{~g})$ concentration in mixed gas (unit: ppb v/v) caused by $\mathrm{FeAsO}_{4}$ decomposition. Figure 8(a3) and (b3) show the conversion 
ratio of $\mathrm{FeAsO}_{4}$.

The vaporization curves of $\mathrm{As}_{2} \mathrm{O}_{3}(\mathrm{~g})$ obtained with various frequency factors $\left(1 \times 10^{7}-1 \times 10^{9}\right)$ and activation energies (120-160) were compared to the mass loss rates of char at $1373 \mathrm{~K}-1773 \mathrm{~K}$. From Figure 8(a1) vs. (a2) the frequency factor was determined to be $1 \times 10^{8} 1 / \mathrm{s}$. Combining Figure 8(b1) vs. (b2), the activation energy was determined to be $140 \mathrm{~kJ} / \mathrm{mol}$. The kinetic parameters of R14 were further applied and validated by other coal combustion conditions. Overall, the reaction kinetic parameters for R14 were determined with $k_{0} \_$R14 $=1 \times 10^{8} 1 / \mathrm{s}$ and $E_{0}{ }_{\mathrm{R} 14}=140 \mathrm{~kJ} / \mathrm{mol}$.

\subsubsection{2 $\mathrm{Ca}_{3}\left(\mathrm{AsO}_{4}\right)_{2}$}

Taking KY coal as an example, the determination process of the frequency factor $\left(k_{0 \_}{ }_{15}\right)$ and activation energy $\left(E_{0}{ }_{-} 15\right)$ with regard to $\mathrm{Ca}_{3}\left(\mathrm{AsO}_{4}\right)_{2}$ decomposition is shown in Figure 9, with three subfigures (a) at $2473 \mathrm{~K}$ (complete decomposition [20]), (b) at $2173 \mathrm{~K}$ (partial decomposition) and (c) at $1773 \mathrm{~K}$ (start of decomposition). Since $\mathrm{Ca}_{3}\left(\mathrm{AsO}_{4}\right)_{2}$ decomposes along with the char combustion process, the mass loss ratio and mass loss rate of char during single coal particle combustion were computed as shown in Figure 9(a1), (b1) and (c1). Figure 9(a2), (b2) and (c2) show the temporal change of $\mathrm{As}_{2} \mathrm{O}_{3}(\mathrm{~g})$ concentration in mixed gas (unit: ppb v/v) caused by $\mathrm{Ca}_{3}\left(\mathrm{AsO}_{4}\right)_{2}$ decomposition. Figure 9(a3), (b3) and (c3) show the conversion ratio of $\mathrm{Ca}_{3}\left(\mathrm{AsO}_{4}\right)_{2}$.

The vaporization curves of $\mathrm{As}_{2} \mathrm{O}_{3}(\mathrm{~g})$ obtained with various frequency factors and activation energies were compared to the mass loss rates of char at $1773 \mathrm{~K}-2473 \mathrm{~K}$. The frequency factor was determined to be $1 \times 10^{8} 1 / \mathrm{s}$. From Figure 9 it can be seen that the residence time range for char combustion is $22-42 \mathrm{~ms}$ at $1773 \mathrm{~K}, 15-30 \mathrm{~ms}$ at $2173 \mathrm{~K}$ and $14-25 \mathrm{~ms}$ at $2473 \mathrm{~K}$. In order to share the same time range with char combustion, the activation energy of R15 was reduced from $160-200 \mathrm{~kJ} / \mathrm{mol}$ to the determined value $160 \mathrm{~kJ} / \mathrm{mol}$. Then the kinetic parameters of $\mathrm{R} 15$ were applied to other coal combustion conditions for validation. Overall, the reaction kinetic parameters for R15 were determined to be $k_{0 \_ \text {R } 15}=1 \times 10^{8} 1 / \mathrm{s}$ and $E_{0 \_} \mathrm{R} 15=160 \mathrm{~kJ} / \mathrm{mol}$.

From the determination process above, one can first obtain the boundary conditions by experiment (the vaporized yield of arsenic), then combining with other parameters (the specific vaporization characteristics of different arsenic species, along with volatile or char), the intermediate vaporization process, namely the chemical kinetics may be determined.

In this way, the chemical reaction kinetics of arsenic compounds were determined as shown in 
Table 6.

Table 6. Chemical reaction kinetics of arsenic compounds

\begin{tabular}{|c|c|c|c|c|}
\hline No. & Chemical reactions & Reaction rate- $R_{\mathrm{i}}$ & $\begin{array}{l}\text { Frequency } \\
\text { factor- } k_{\mathrm{i}}\end{array}$ & $\begin{array}{l}\text { Activation } \\
\text { energy- } \\
E_{\mathrm{i}}, \mathrm{kJ} / \mathrm{mol}\end{array}$ \\
\hline R6 & As-org $+\mathrm{O}_{2}=\mathrm{As}_{2} \mathrm{O}_{3}(\mathrm{~g})$ & $\begin{array}{l}R_{6}=k_{6} \exp \left(-E_{6} / R T\right) C_{A s-o r g} C_{O_{2}} \\
\mathrm{~mol} /\left(\mathrm{m}^{3} \cdot \mathrm{s}\right)\end{array}$ & $\begin{array}{l}10^{8}-10^{9} \\
\mathrm{~m}^{3} /(\mathrm{mol} \cdot \mathrm{s})\end{array}$ & 55 \\
\hline $\mathrm{R} 13$ & $3 \mathrm{FeAsS}+7.25 \mathrm{O}_{2}=\mathrm{Fe}_{3} \mathrm{O}_{4}+3 / 2 \mathrm{As}_{2} \mathrm{O}_{3}(\mathrm{~g})+3 \mathrm{SO}_{2}$ & $\begin{array}{l}R_{13}=k_{13} \exp \left(-E_{13} / R T\right) \times S \times P_{O_{2}} \\
\mathrm{~mol} / \mathrm{s}\end{array}$ & $\begin{array}{l}2 \times 10^{3} \\
(\mathrm{~mol} \cdot \mathrm{m}) /(\mathrm{Pa} \cdot \mathrm{s})\end{array}$ & 90 \\
\hline R14 & $\mathrm{FeAsO}_{4}=1 / 3 \mathrm{Fe}_{3} \mathrm{O}_{4}+1 / 2 \mathrm{As}_{2} \mathrm{O}_{3}(\mathrm{~g})+7 / 12 \mathrm{O}_{2}$ & $\begin{array}{l}R_{14}=k_{14} \exp \left(-E_{14} / R T\right) \times n_{\text {eeAs }_{4}} \\
\mathrm{~mol} / \mathrm{s}\end{array}$ & $1 \times 10^{8}, 1 / \mathrm{s}$ & 140 \\
\hline $\mathrm{R} 15$ & $\mathrm{Ca}_{3}\left(\mathrm{AsO}_{4}\right)_{2}=3 \mathrm{CaO}+\mathrm{As}_{2} \mathrm{O}_{3}(\mathrm{~g})+\mathrm{O}_{2}$ & $\begin{array}{l}R_{15}=k_{15} \exp \left(-E_{15} / R T\right) \times n_{\mathrm{Ca}_{3}\left(\mathrm{AsO}_{4}\right)_{2}} \\
\mathrm{~mol} / \mathrm{s}\end{array}$ & $1 \times 10^{8}, 1 / \mathrm{s}$ & 160 \\
\hline
\end{tabular}

Adding the reaction kinetics of arsenic (Table 6) and the vaporized yield model of arsenic compounds (refer to Section 3.2) into the single-particle coal combustion model, a novel vaporization model of arsenic considering reaction kinetics was developed. It should be noted that the vaporized yield of arsenic is a fitting result for experimental data and so different parameters would be determined if the vaporized yield was very different. However, it is encouraging to find that the reaction kinetic parameters, such as the frequency factor and activation energy, can be determined so precisely using a combination of the single-particle combustion characteristics and the physical and thermal properties of arsenic species, and this supports the idea that this approach can lead to a realistic determination of arsenic reaction kinetics.

\section{Conclusions}

The reaction kinetics of four arsenic species (As-org, $\mathrm{FeAsS}, \mathrm{FeAsO}_{4}$ and $\left.\mathrm{Ca}_{3}\left(\mathrm{AsO}_{4}\right)_{2}\right)$ during coal combustion were determined step by step. The vaporized yields of these arsenic species were fitted experimentally based on the initial conditions. Since arsenic vaporization occurs along with the coal combustion process, a single-particle coal combustion model that allows both the temporal and spatial change of gas concentrations was established. The combustion characteristics of volatile matter and char were used as additional means of validating the results. The thermodynamic properties of the arsenic species were also taken into account. Combining all the conditions together, the intermediate vaporization process of arsenic can be determined as a result, providing the oxidation/decomposition reaction kinetics. It is a promising result to find 
that the reaction kinetic parameters, the frequency factor and activation energy, can be determined so precisely in terms of the order of magnitude despite the variation of coal sample and temperature conditions, and we believe that this approach provides a new method to determine the chemical kinetics of arsenic compounds given the challenges of doing this experimentally.

Adding the reaction kinetics of arsenic and the vaporized yield model of arsenic compounds into the single-particle coal combustion model, a novel vaporization model of arsenic considering reaction kinetics variation of various arsenic species was developed. Furthermore, the temporal-spatial evolution of both gaseous arsenic and the vaporization ratio of arsenic could be predicted to explore the vaporization mechanism of arsenic as well as the effects of combustion factors. The application of this model is shown in detail in this work.

\section{Acknowledgements}

The authors gratefully acknowledged the financial support from the National Key R\&D Plan (No. 2016YFB0600701) and the Fundamental Research Funds for the Central Universities (No. 2018ZD03).

\section{Nomenclature}

Parameter $=$ Description

$A=$ particle area with diameter $d_{\mathrm{p}}\left(\mathrm{m}^{2}\right)$

$c_{p s}=$ specific heat capacity of gas inside the particle $(\mathrm{J} /(\mathrm{kg} \cdot \mathrm{K}))$

$c_{p g}=$ specific heat capacity of gas in the boundary layer $(\mathrm{J} /(\mathrm{kg} \cdot \mathrm{K}))$

$C=$ molar concentration of a certain gas component $\left(\mathrm{kmol} / \mathrm{m}^{3}\right)$

$C_{g s}=$ molar concentration of gas inside the particle $\left(\mathrm{kmol} / \mathrm{m}^{3}\right)$

$C_{g g}=$ molar concentration of gas in the boundary layer $\left(\mathrm{kmol} / \mathrm{m}^{3}\right)$

$d_{\mathrm{p}}=$ particle diameter, in microns $(\mathrm{m})$

$D^{\mathrm{e}}=$ effective diffusion coefficient of gas inside the particle $\left(\mathrm{m}^{2} / \mathrm{s}\right)$

$D_{b u l k}=$ molecular diffusion coefficient of bulk gas $\left(\mathrm{m}^{2} / \mathrm{s}\right)$

$E_{i}=$ activation energy of reaction $i(\mathrm{~kJ} / \mathrm{mol})$

$h=$ surface heat convection coefficient $\left(\mathrm{W} /\left(\mathrm{m}^{2} \cdot \mathrm{K}\right)\right)$

$k_{i}=$ frequency factor of reaction $i$ (unit changes with reaction order and reaction type)

$k_{m}=$ mass transfer coefficient $(\mathrm{m} / \mathrm{s})$

$L_{0}=$ total pore length per unit volume $\left(\mathrm{m} / \mathrm{m}^{3}\right)$ 
$m_{0}=$ initial amount of arsenic in coal $(\mathrm{kg})$

$m_{\mathrm{v}}=$ vaporized amount of arsenic $(\mathrm{kg})$

$m_{s}=$ mass weight of a certain solid components inside the particle $(\mathrm{kg})$

$M_{s}=$ molecular weight of a certain solid component inside the particle $(\mathrm{kg})$

$\dot{m}_{g s}=$ mass concentration of a certain gas inside the particle $\left(\mathrm{kg} / \mathrm{m}^{3}\right)$

$\dot{m}_{g N}=$ mass concentration of a certain gas at the external surface of the particle $\left(\mathrm{kg} / \mathrm{m}^{3}\right)$

$\dot{m}_{g g}=$ mass concentration of a certain gas in the boundary layer $\left(\mathrm{kg} / \mathrm{m}^{3}\right)$

$\dot{m}_{\text {bulk }}=$ mass concentration of a certain gas in bulk gas $\left(\mathrm{kg} / \mathrm{m}^{3}\right)$

$n=$ mole number of a certain component (mol)

$N=$ number of discretization shells of a single particle (-)

$P=$ partial pressure of a gas component $(\mathrm{Pa})$

$r=$ radius of particle with diameter $d_{\mathrm{p}}(\mathrm{m})$

$R_{\mathrm{i}}=$ the rate of reaction $i\left(\mathrm{~mol} /\left(\mathrm{m}^{3} \cdot \mathrm{s}\right)\right.$ or $\left.\mathrm{mol} / \mathrm{s}\right)$

$R_{v o l}=$ devolatilization rate of coal particle (1/s)

$S=$ specific surface area of char particle $\left(\mathrm{m}^{2} / \mathrm{m}^{3}\right)$

$S_{0}=$ specific surface area at zero carbon burn-off for devolatilized char $\left(\mathrm{m}^{2} / \mathrm{m}^{3}\right)$

$t=$ time (s)

$T=$ temperature $(\mathrm{K})$

$T_{S}=$ temperature inside the particle $(\mathrm{K})$

$T_{N}=$ temperature at the external surface of the particle $(\mathrm{K})$

$T_{g}=$ temperature in the boundary layer $(\mathrm{K})$

$T_{\text {bulk }}=$ temperature of bulk gas $(\mathrm{K})$

$T_{\text {wall }}=$ temperature of environmental wall (K)

$V=$ mass fraction of volatiles in the coal $(-)$

$V_{0}=$ initial mass fraction of volatiles in the coal (-)

$V_{g s}=$ gas volume in the $j$-th particle shell $\left(\mathrm{m}^{3}\right)$

$X_{j}=$ char conversion ratio of the $j$-th particle shell (-)

\section{Greek characters}

$\alpha / \beta=$ molar ratio of $\mathrm{CO} / \mathrm{CO}_{2}(-)$ 
$\delta_{r}=$ boundary layer thickness $(\mathrm{m})$

$\varepsilon_{j}=$ char porosity of the $j$-th shell (-)

$\varepsilon_{j}^{0}=$ initial char porosity of the $j$-th shell $(-)$

$\varepsilon_{\text {rad }}=$ radiation emissivity of coal particle $(-)$

$\eta=$ vaporized yield of arsenic (-)

$\lambda_{e}=$ effective heat conduction coefficient of gas inside the particle $(\mathrm{W} /(\mathrm{m} \cdot \mathrm{K}))$

$\lambda_{\text {bulk }}=$ heat conduction coefficient of bulk gas $(\mathrm{W} /(\mathrm{m} \cdot \mathrm{K}))$

$\rho_{s}=$ gas density inside the particle $\left(\mathrm{kg} / \mathrm{m}^{3}\right)$

$\rho_{g}=$ gas density in the boundary layer $\left(\mathrm{kg} / \mathrm{m}^{3}\right)$

$\sigma=$ Stefan-Boltzmann constant $\left(\mathrm{W} /\left(\mathrm{m}^{2} \cdot \mathrm{K}^{4}\right)\right)$

$\psi=$ the dimensionless parameter known as pore parameter whose value depends on the nature of the coal char, $\psi=4 \pi L_{0}\left(1-\varepsilon_{0}\right) / \mathrm{S}_{0}{ }^{2}(-)$

$\Delta H_{\mathrm{i}}=$ the heat release of reaction $i(\mathrm{~J} / \mathrm{mol})$

\section{Subscripts}

$s=$ inside particle

$g=$ in gas boundary layer

\section{References}

[1] W.P. Linak, J.O.L. Wendt, Toxic metal emissions from incineration: mechanisms and control, Prog. Energy Combust. Sci. 19 (1993) 145-185.

[2] C. Wang, H. Liu, Y. Zhang, C. Zou, E. Anthony, Review of arsenic behavior during coal combustion: volatilization, transformation, emission and removal technologies, Energy Combust. Sci. 68 (2018) 1-28.

[3] C.L. Senior, L.E. Bool III, J.R. Morency, Laboratory study of trace element vaporization from combustion of pulverized coal, Fuel Process. Technol. 63 (2000) 109-124.

[4] C.L. Senior, L.E. Bool III, S. Srinivasachar, B.R. Pease, K. Porle, Pilot scale study of trace element vaporization and condensation during combustion of a pulverized sub-bituminous coal, Fuel Process. Technol. 63 (2000) 149-165.

[5] C.L. Senior, D.O. Lignell, A.F. Sarofim, A. Mehta, Modeling arsenic partitioning in coal-fired power plants, Combust. Flame 147 (2006) 209-221. 
[6] H. Tian, K. Liu, J. Zhou, L. Lu, J. Hao, P. Qiu, J. Gao, C. Zhu, K. Wang, S. Hua, Atmospheric emission inventory of hazardous trace elements from China's coal-fired power plants: temporal trends and spatial variation characteristics, Environ. Sci. Technol. 48 (2014) 3575-3582.

[7] National emission standards for hazardous air pollutants from coal and oil-fired electric utility steam generating units and standards of performance for fossil-fuel-fired electric utility, industrial-commercialinstitutional, and small industrial-commercial-institutional steam generating units; Technical correction, in: E.P. Agency (Ed.), 2016.

[8] Y. Zhao, J. Zhang, W. Huang, Z. Wang, Y. Li, D. Song, F. Zhao, C. Zheng, Arsenic emission during combustion of high arsenic coals from Southwestern Guizhou, China, Energy Convers. Manage. 49 (2008) 615-624.

[9] L.E.I. Bool, J.J. Helble, A laboratory study of the partitioning of trace elements during pulverized coal combustion, Energy Fuels 9 (1995) 880-887.

[10] G.P. Huffman, F.E. Huggins, N. Shah, J. Zhao, Speciation of arsenic and chromium in coal and combustion ash by XAFS spectroscopy, Fuel Process. Technol. 39 (1994) 47-62.

[11] P. Shah, V. Strezov, K. Prince, P.F. Nelson, Speciation of As, Cr, Se and Hg under coal fired power station conditions, Fuel 87 (2008) 1859-1869.

[12] Y.E. Yudovich, M.P. Ketris, Arsenic in coal: a review, Int. J. Coal Geol. 61 (2005) 141-196.

[13] H. Hu, H. Liu, J. Chen, A. Li, H. Yao, Speciation transformation of arsenic during municipal solid waste incineration, Proc. Combust. Inst. 35 (2015) 2883-2890.

[14] H. Liu, C. Wang, Y. Zhang, X. Huang, Y. Guo, J. Wang, Experimental and modeling study on the volatilization of arsenic during co-combustion of high arsenic lignite blends, Appl. Therm. Eng. 108 (2016) 1336-1343.

[15] R.A. Jadhav, L.-S. Fan, Capture of gas-phase arsenic oxide by lime: kinetic and mechanistic studies, Environ. Sci. Technol. 35 (2001) 794-799.

[16] W.S. Seames, J.O.L. Wendt, Regimes of association of arsenic and selenium during pulverized coal combustion, Proc. Combust. Inst. 31 (2007) 2839-2846.

[17] Y. Zhang, C. Wang, H. Liu, Experiment and mechanism research on gas-phase $\mathrm{As}_{2} \mathrm{O}_{3}$ adsorption of $\mathrm{Fe}_{2} \mathrm{O}_{3} / \gamma-\mathrm{Al}_{2} \mathrm{O}_{3}$, Fuel 181 (2016) 1034-1040.

[18] Y. Li, H. Tong, Y. Zhuo, Y. Li, X. Xu, Simultaneous removal of $\mathrm{SO}_{2}$ and trace $\mathrm{As}_{2} \mathrm{O}_{3}$ from flue gas: mechanism, kinetics study, and effect of main gases on arsenic capture, Environ. Sci. Technol. 41 (2007) 2894-2900.

[19] F. Low, L. Zhang, Arsenic emissions and speciation in the oxy-fuel fly ash collected from lab-scale drop-tube furnace, Proc. Combust. Inst. 34 (2013) 2877-2884 
[20] H. Liu, C. Wang, X. Sun, Y. Zhang, C. Zou, Volatilization of arsenic in coal during isothermal oxyfuel combustion, Energy Fuels 30 (2016) 3479-3487.

[21] H. Liu, C. Wang, C. Zou, Y. Zhang, J. Wang, Simultaneous volatilization characteristics of arsenic and sulfur during isothermal coal combustion, Fuel 203 (2017) 152-161.

[22] C. Zou, C. Wang, H. Liu, H. Wang, Y. Zhang, Effect of volatile and ash contents in coal on the volatilization of arsenic during isothermal coal combustion, Energy Fuels 31 (2017) 12831-12838.

[23] F. Shen, J. Liu, Z. Zhang, J. Dai, On-line analysis and kinetic behavior of arsenic release during coal combustion and pyrolysis, Environ. Sci. Technol. 49 (2015) 13716-13723.

[24] T. Zeng, A.F. Sarofim, C.L. Senior, Vaporization of arsenic, selenium and antimony during coal combustion, Combust. Flame 126 (2001) 1714-1724.

[25] M. Bissen, F.H. Frimmel, Arsenic - a review. Part I: occurrence, toxicity, speciation, mobility, CLEAN-Soil, Air, Water 31 (2003) 9-18.

[26] H. Liu, W.-P. Pan, C. Wang, Y. Zhang, Volatilization of arsenic during coal combustion based on isothermal thermogravimetric analysis at $600-1500^{\circ} \mathrm{C}$, Energy Fuels 30 (2016) 6790-6798.

[27] C. Wang, H. Shao, M. Lei, Y. Wu, L. Jia, Effect of the coupling action between volatiles, char and steam on isothermal combustion of coal char, Appl. Therm. Eng. 93 (2016) 438-445.

[28] C. Wang, X. Zhou, L. Jia, Y. Tan, Sintering of limestone in calcination/carbonation cycles, Ind. Eng. Chem. Res. 53 (2014) 16235-16244.

[29] H. Liu, C. Wang, Y. Zhang, Z. Sun, H. Shao, Effect of temperature and mode of occurrence on the migration and volatilization of arsenic during coal combustion, J. Chem. Ind. Eng. (China) 66 (2015) 4643-4651.

[30] H.S. Caram, N.R. Amundson, Diffusion and reaction in a stagnant boundary layer about a carbon particle, Ind. Eng. Chem. Fundam. 16 (1977) 171-181.

[31] E. Mon, N.R. Amundson, Diffusion and reaction in a stagnant boundary layer about a carbon particle. 2. An extension, Ind. Eng. Chem. Fundam. 17 (1978) 313-321.

[32] K. Xu, H. Zhang, Y. Wu, M. Baroncelli, H. Pitsch, Transient model for soot formation during the combustion of single coal particles, Proc. Combust. Inst. 36 (2017) 2131-2138.

[33] Y. Niu, C.R. Shaddix, A sophisticated model to predict ash inhibition during combustion of pulverized char particles, Proc. Combust. Inst. 35 (2015) 561-569.

[34] T. Maffei, R. Khatami, S. Pierucci, T. Faravelli, E. Ranzi, Y.A. Levendis, Experimental and modeling study of single coal particle combustion in $\mathrm{O}_{2} / \mathrm{N}_{2}$ and Oxy-fuel $\left(\mathrm{O}_{2} / \mathrm{CO}_{2}\right)$ atmospheres, Combust. Flame 160 (2013) 2559-2572.

[35] A.K. Sadhukhan, P. Gupta, R.K. Saha, Modeling and experimental studies on single particle coal devolatilization and residual char combustion in fluidized bed, Fuel 90 (2011) 2132-2141. 
[36] W. Fu, Y. Zhang, H. Han, D. Wang, Universal model for coal pyrolysis (Fu-Zhang model), Science in China (Series A) 31 (1988) 1283-1290.

[37] S.K. Bhatia, D.D. Perlmutter, A random pore model for fluid-solid reactions: I. Isothermal, kinetic control, AlChE J. 27 (1981) 379-386.

[38] D.R. Gregory, R.F. Littlejohn, Survey of numerical data on the thermal decomposition of coal. [Review with 88 references], Br.coal Util.res.assoc.mon.bull 29:6 (1965) A36.

[39] Z. Chen, M. Lin, J. Ignowski, B. Kelly, T.M. Linjewile, P.K. Agarwal, Mathematical modeling of fluidized bed combustion. 4: $\mathrm{N}_{2} \mathrm{O}$ and $\mathrm{NO}_{\mathrm{x}}$ emissions from the combustion of char, Fuel 80 (2001) 12591272.

[40] Z. Zhang, D. Chen, Z. Li, N. Cai, J. Imada, Development of Sulfur Release and Reaction Model for CFD Modeling in Sub-bituminous Coal Combustion, Energy Fuels 31 (2017) 1383-1398.

[41] J. Tomeczek, H. Palugniok, Kinetics of mineral matter transformation during coal combustion, Fuel 81 (2002) 1251-1258.

[42] O. Sitnai, Solids mixing in a fluidized bed with horizontal tubes, Ind. Eng. Chem. Process Des. Dev 20 (1981) 533-538.

[43] R.H. Borgwardt, Kinetics of the reaction of sulfur dioxide with calcined limestone, Environ. Sci. Technol. 4 (1970) 59-63.

[44] B. Goshayeshi, J.C. Sutherland, A comparison of various models in predicting ignition delay in single-particle coal combustion, Combust. Flame 161 (2014) 1900-1910.

[45] J. McConnell, J.C. Sutherland, The effect of model fidelity on prediction of char burnout for singleparticle coal combustion, Proc. Combust. Inst. 36 (2017) 2165-2172.

[46] H. Lee, S. Choi, An observation of combustion behavior of a single coal particle entrained into hot gas flow, Combust. Flame 162 (2015) 2610-2620.

[47] J. Riaza, J. Gibbins, H. Chalmers, Ignition and combustion of single particles of coal and biomass, Fuel 202 (2017) 650-655.

[48] G. Simões, D. Magalhães, M. Rabaçal, M. Costa, Effect of gas temperature and oxygen concentration on single particle ignition behavior of biomass fuels, Proc. Combust. Inst. 36 (2017) 22352242 . 


\section{Figure Captions}

Figure 1. Experimental system of arsenic vaporization during coal combustion

Figure 2. Comparison of the predicted and experimental vaporization ratio of arsenic in coals at various temperatures

Figure 3. Single-particle schematic: the particle is divided into $N$ spherical shells $(j=1$ to $N$ ) of equal thickness

Figure 4. Flow diagram of the computing process

Figure 5. Temporal-spatial combustion characteristics of single KY coal particle, 1173K vs. $1773 \mathrm{~K}, j=1-18$

Figure 6. Determination of the frequency factor of R6 (organic arsenic oxidation)

Figure 7. Determination of the frequency factor of R13 (FeAsS oxidation)

Figure 8. Determination of the frequency factor and activation energy of $\mathrm{R} 14\left(\mathrm{FeAsO}_{4}\right.$ decomposition)

Figure 9. Determination of the frequency factor and activation energy of $\mathrm{R} 15\left(\mathrm{Ca}_{3}\left(\mathrm{AsO}_{4}\right)_{2}\right.$ decomposition)

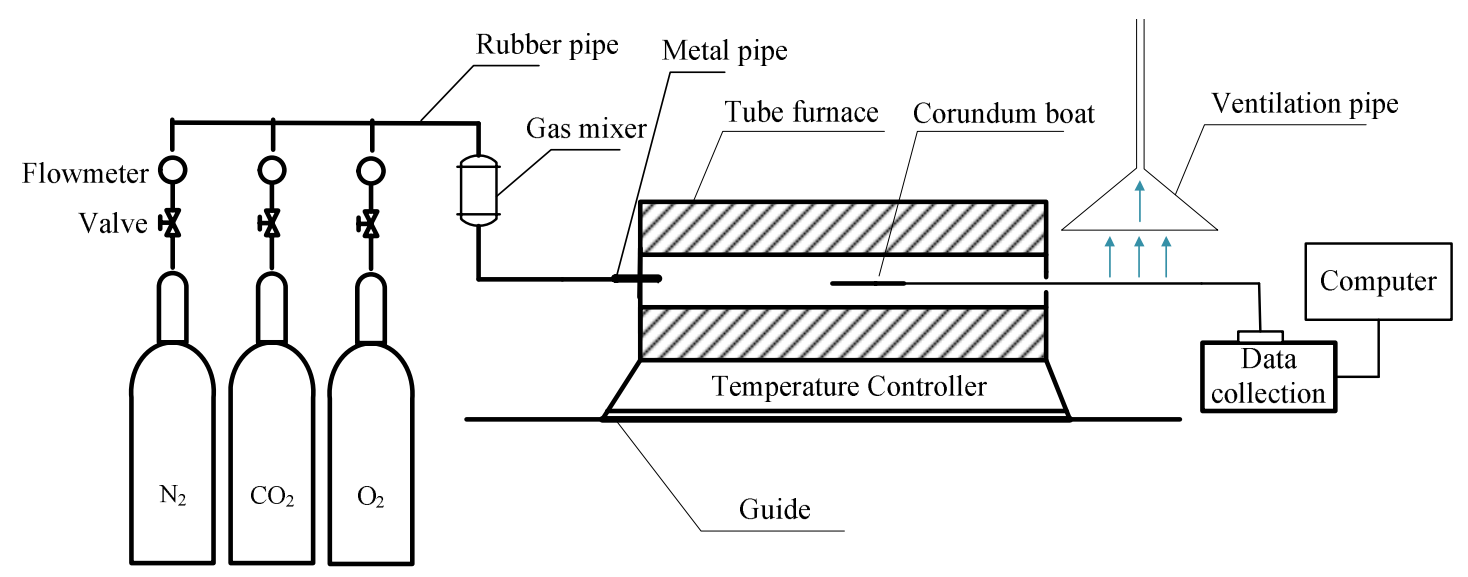

Figure 1. Experimental system of arsenic vaporization during coal combustion 


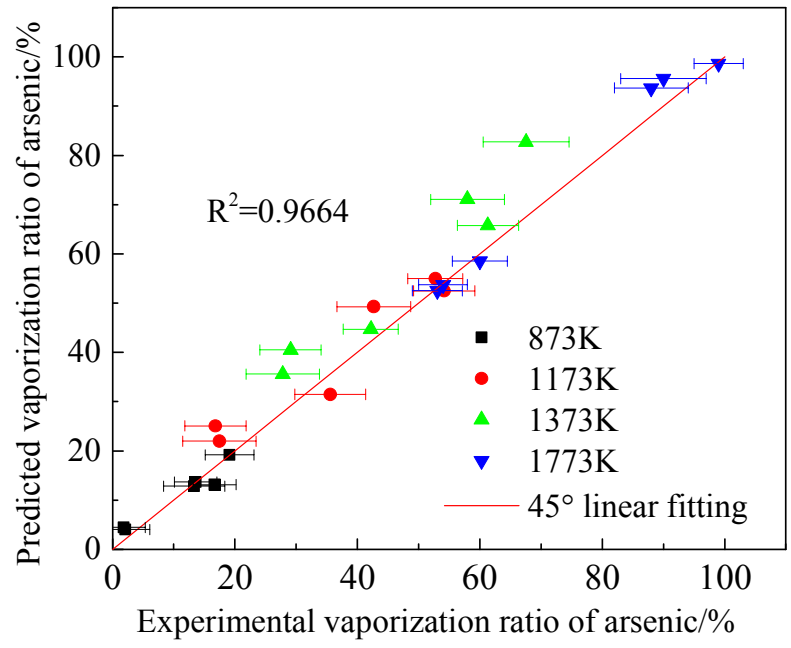

Figure 2. Comparison of the predicted and experimental vaporization ratio of arsenic in coals at various temperatures

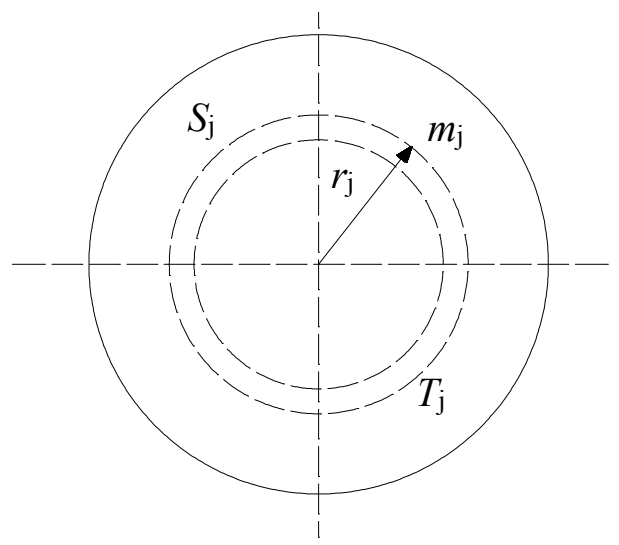

Figure 3. Single-particle schematic: the particle is divided into $N$ spherical shells $(j=1$ to $N$ ) of equal thickness 
Input 1:

- Coal density, volatile and ash content

- Sulfur, arsenic and $\mathrm{CaO}$ content

- Speciation as well as ratio of sulfur and arsenic compounds in coal

Input 2:

- Particle diameter $d_{\mathrm{p}}$, radius $r$

- boundary layer thickness: $2 r$

- divided spherical shells (18 in total)

- Uniform shell thickness $\mathrm{d} r=1 / 6 \times r$;

- Particle:6 shells

- boundary layer: 12 shells

Input 3:

- Bulk gas temperature $\left(\mathrm{T}_{\text {bulk }}\right)$

- Initial char porosity

- Initial gas composition (Air case)

- $\mathrm{C}_{\mathrm{O} 2}=0.21, \mathrm{C}_{\mathrm{N} 2}=0.79$

- Time step: $d t=10^{-6}$ seconds

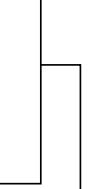

$(2$

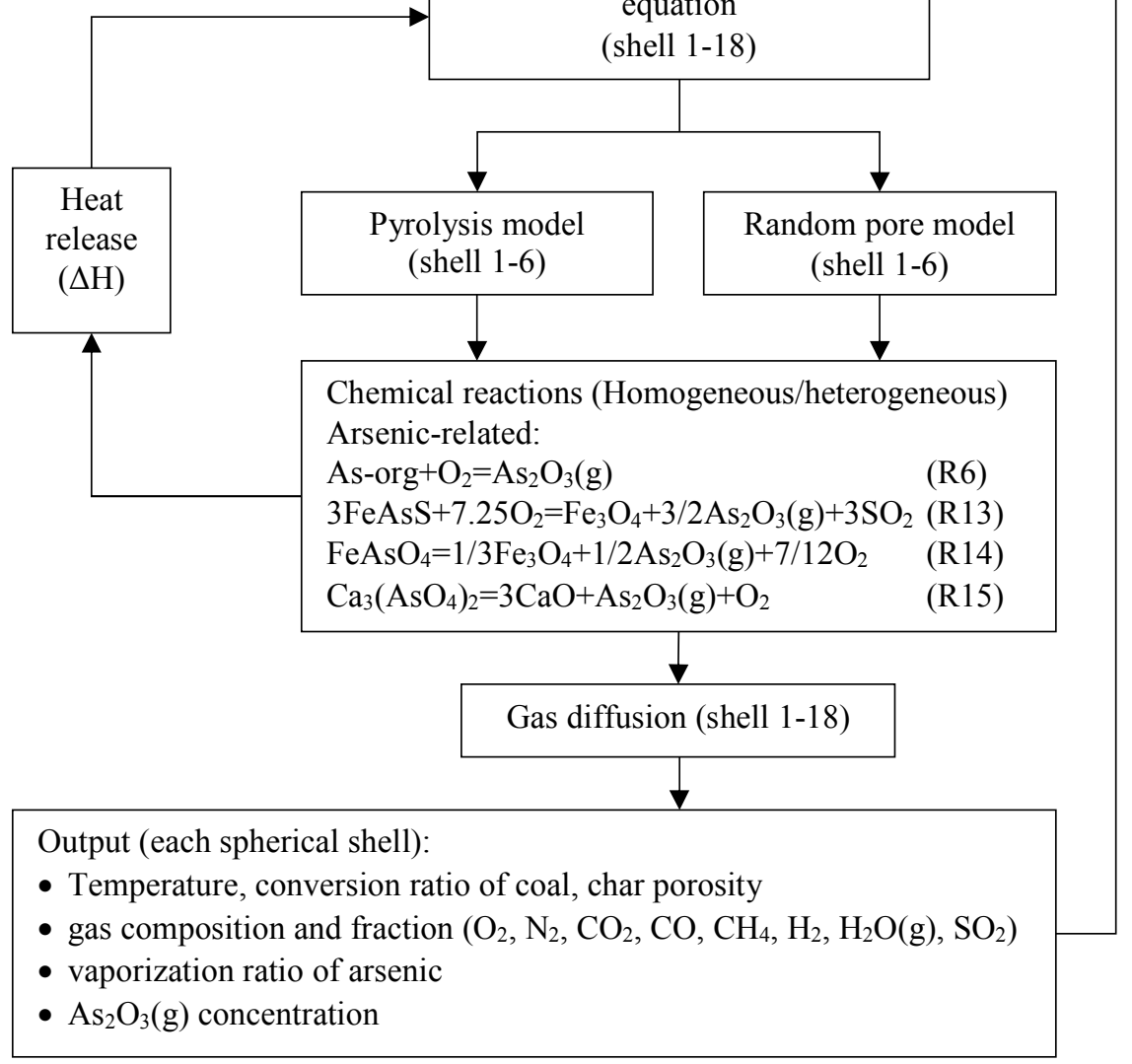

Figure 4. Flow diagram of the computing process 

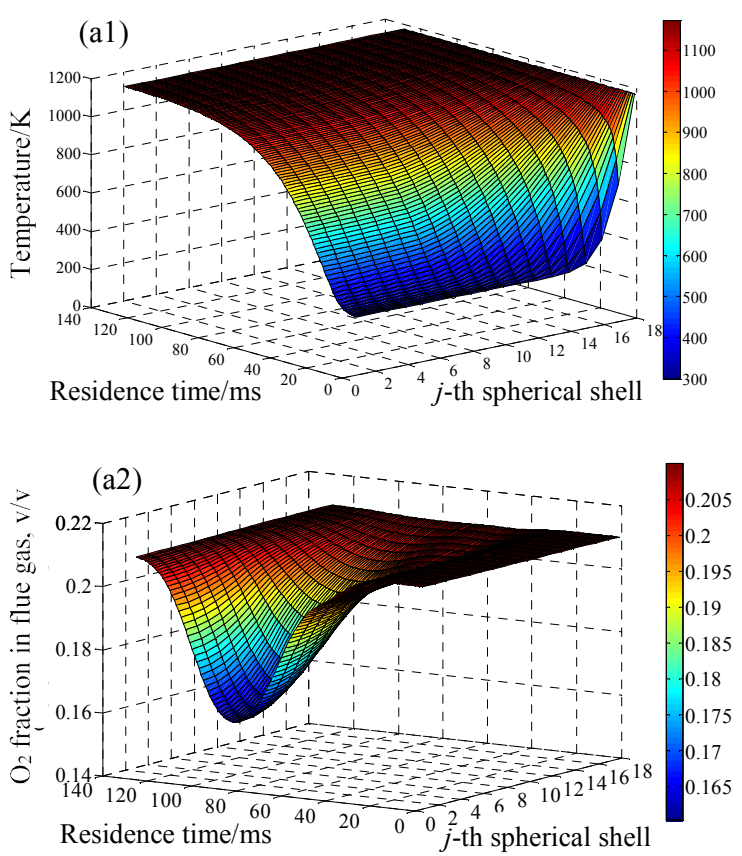

(a3)
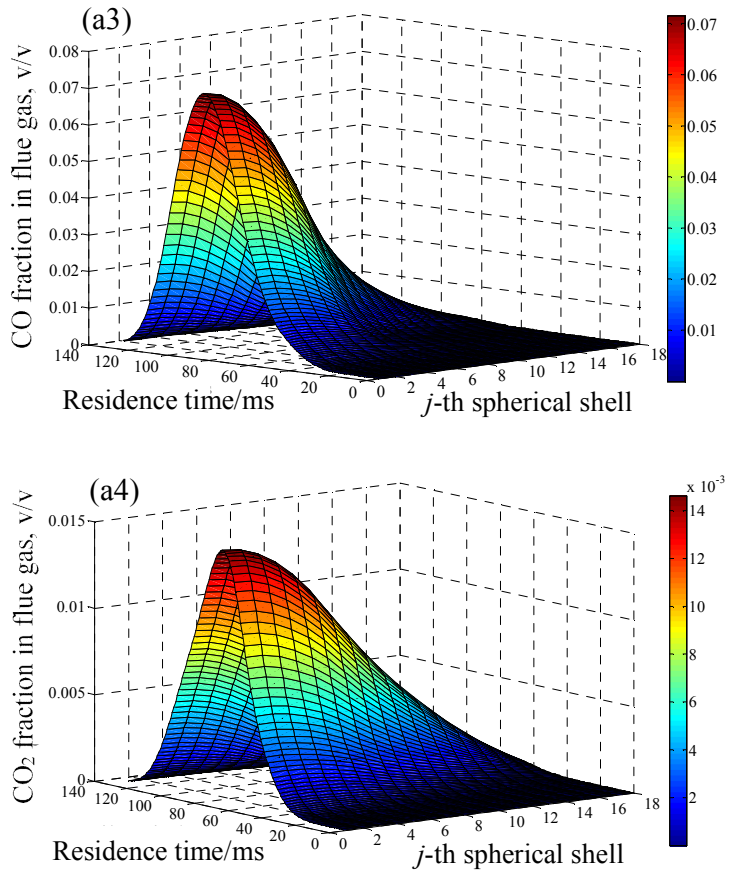

(a) at $1173 \mathrm{~K}$
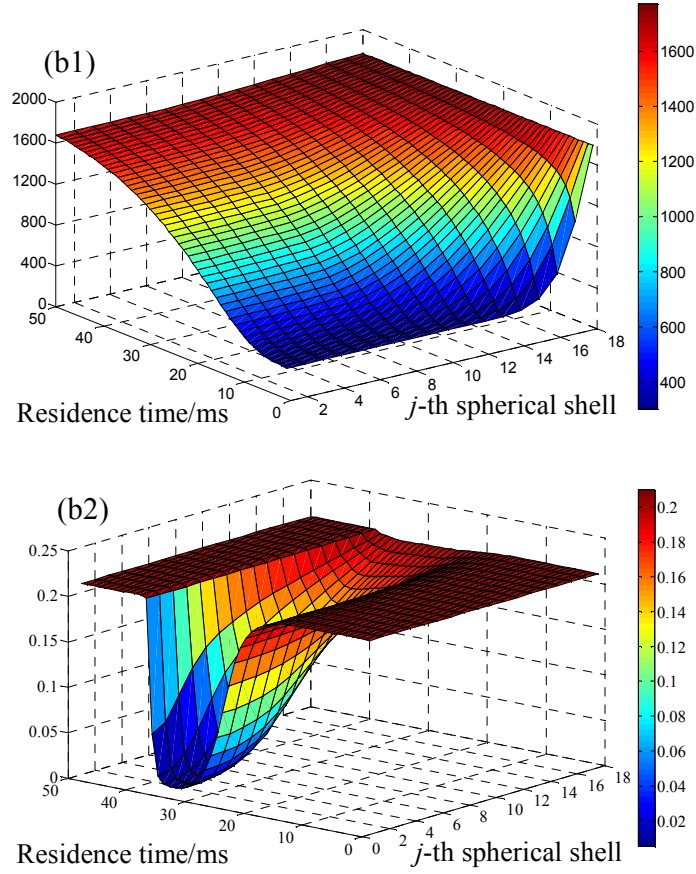

(b3)
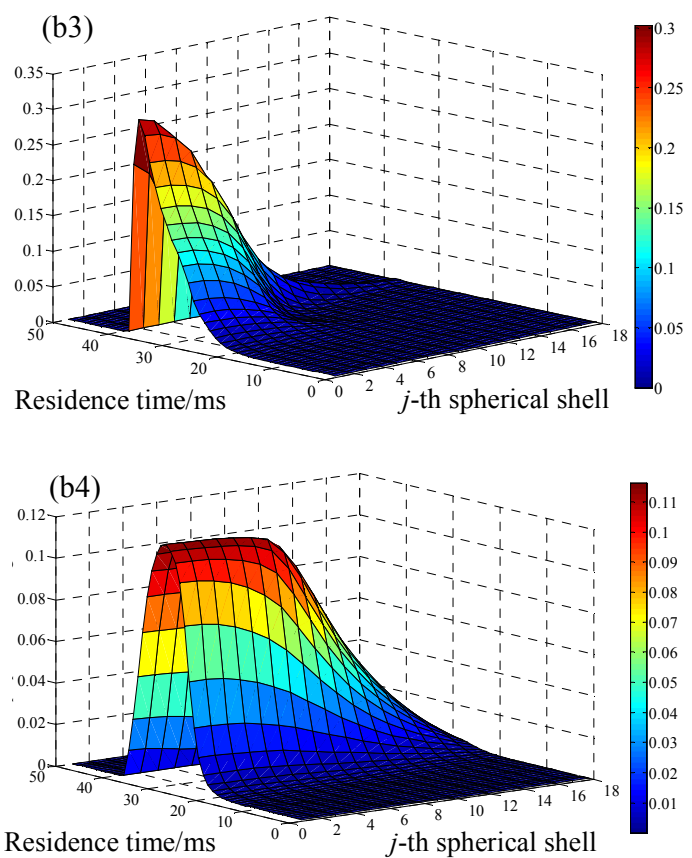

(b) at $1773 \mathrm{~K}$

Figure 5. Temporal-spatial combustion characteristics of single KY coal particle, 1173K vs. $1773 \mathrm{~K}, j=1-18$ 


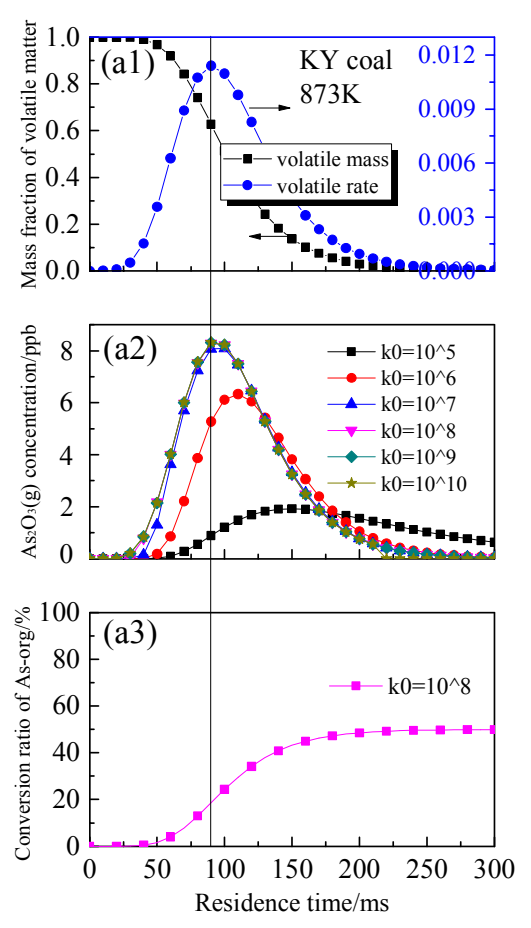

(a) KY coal at $873 \mathrm{~K}$

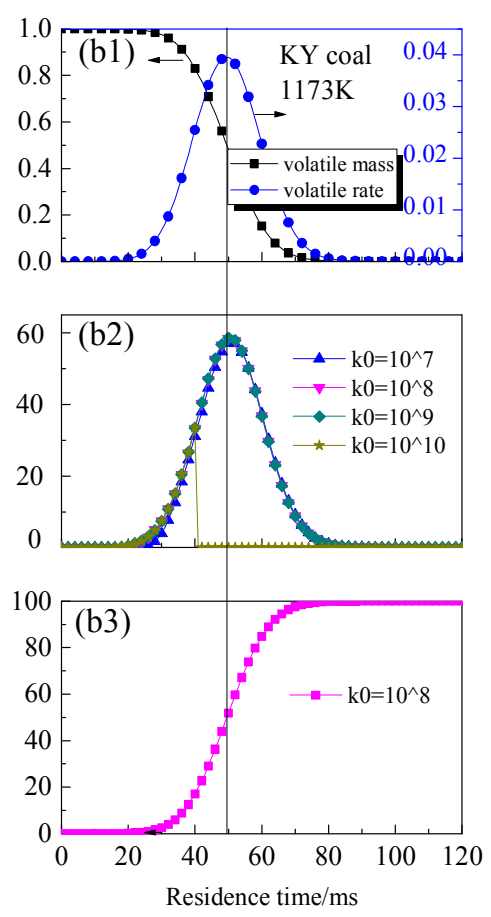

(b) KY coal at $1173 \mathrm{~K}$
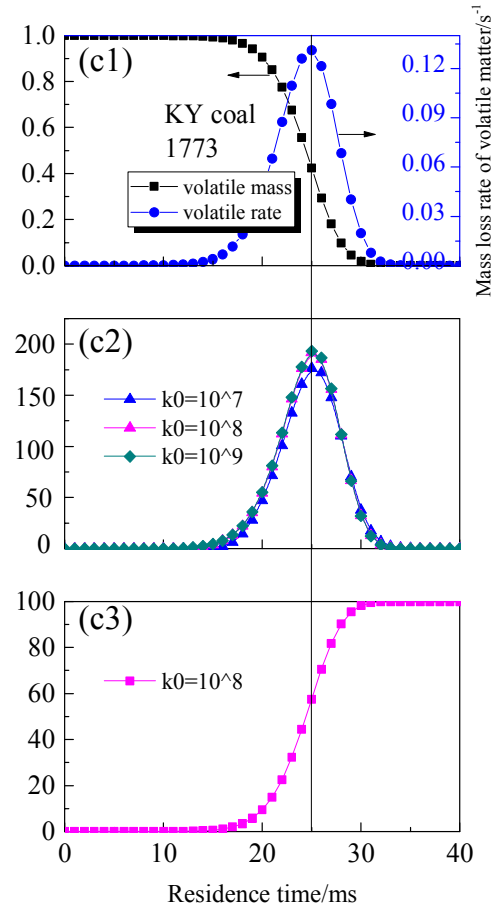

(c) KY coal at $1773 \mathrm{~K}$

Figure 6. Determination of the frequency factor of R6 (organic arsenic oxidation)

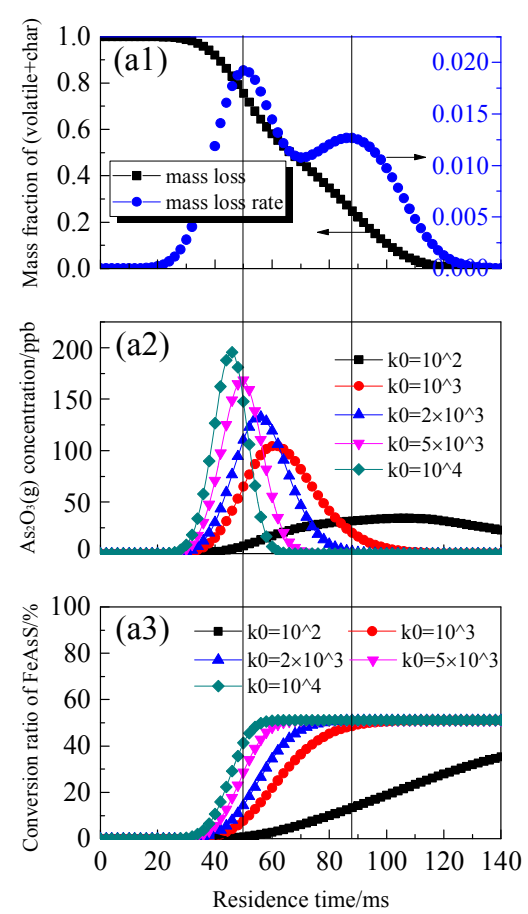

(a) $\mathrm{KY}$ coal at $1173 \mathrm{~K}$

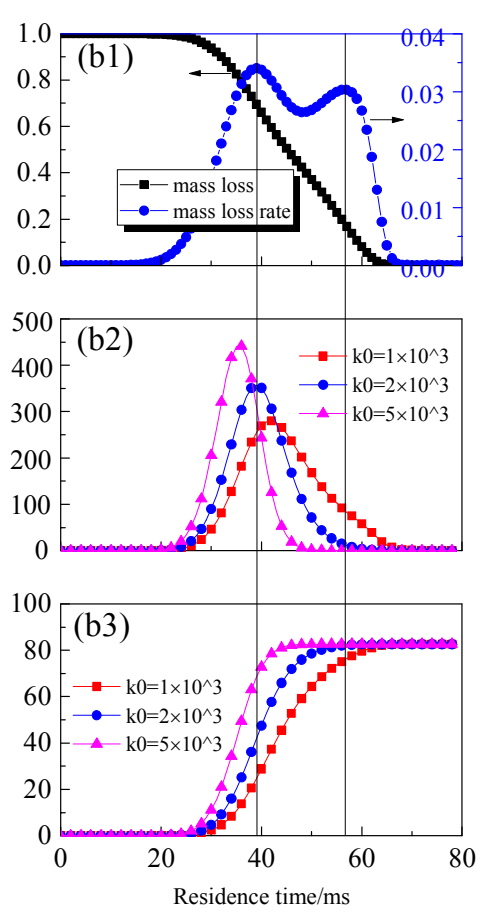

(b) KY coal at $1373 \mathrm{~K}$

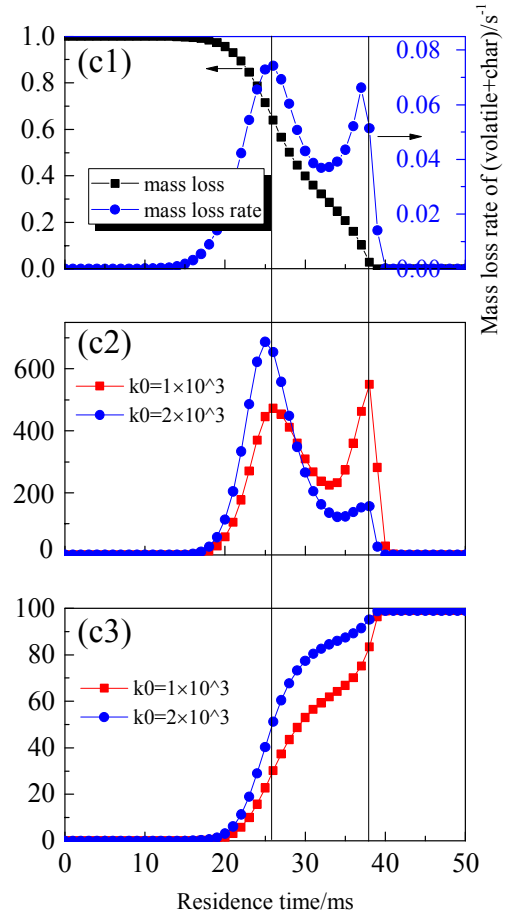

(c) KY coal at $1773 \mathrm{~K}$

Figure 7. Determination of the frequency factor of R13 (FeAsS oxidation) 


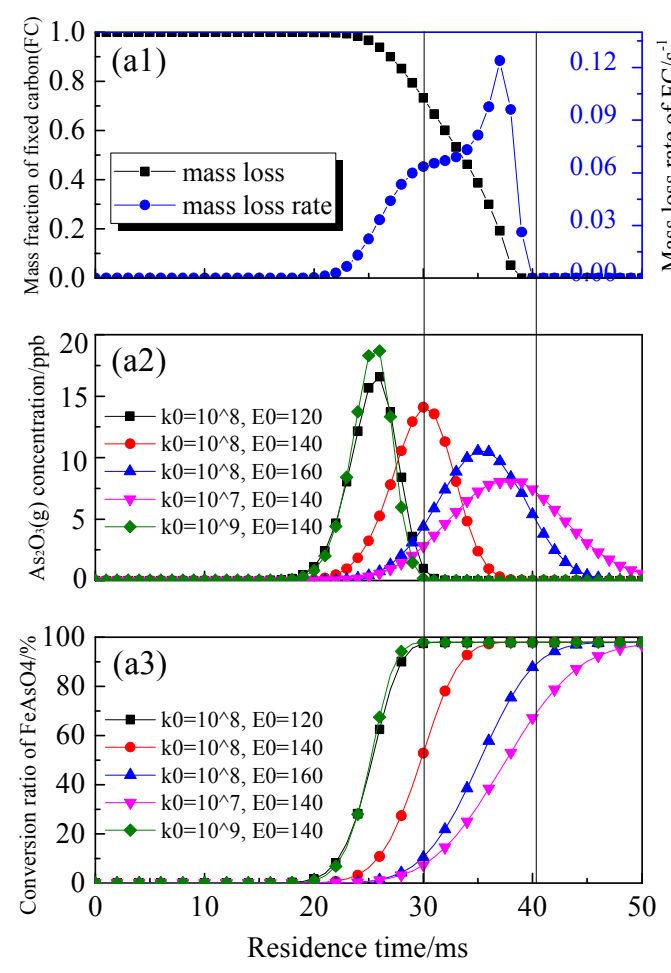

(a) $\mathrm{KY}$ coal at $1773 \mathrm{~K}$

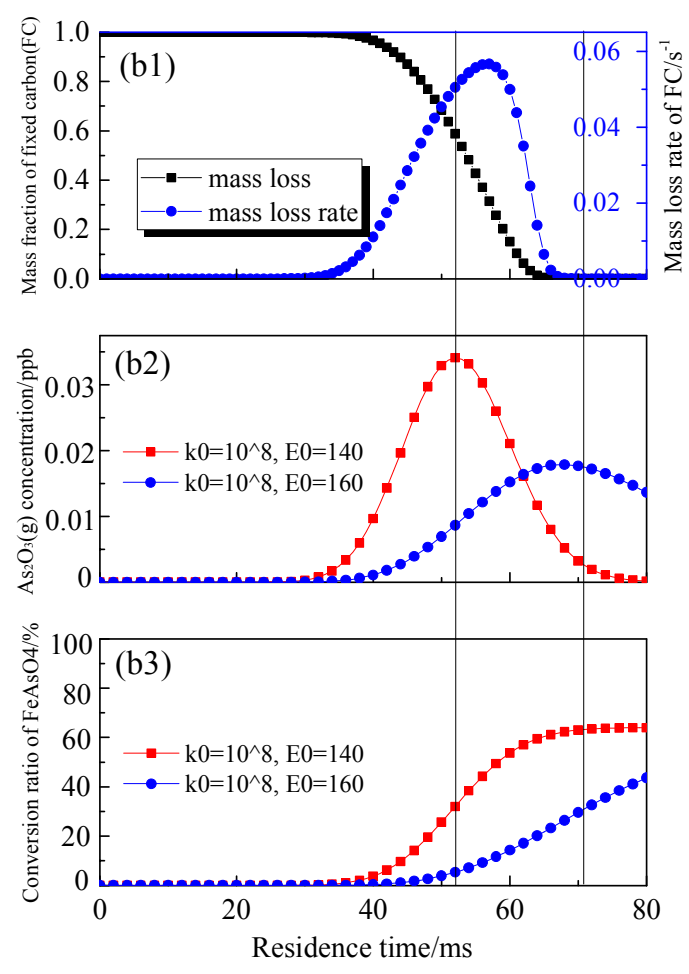

(b) KY coal at $1373 \mathrm{~K}$

Figure 8. Determination of the frequency factor and activation energy of $\mathrm{R} 14\left(\mathrm{FeAsO}_{4}\right.$ decomposition)
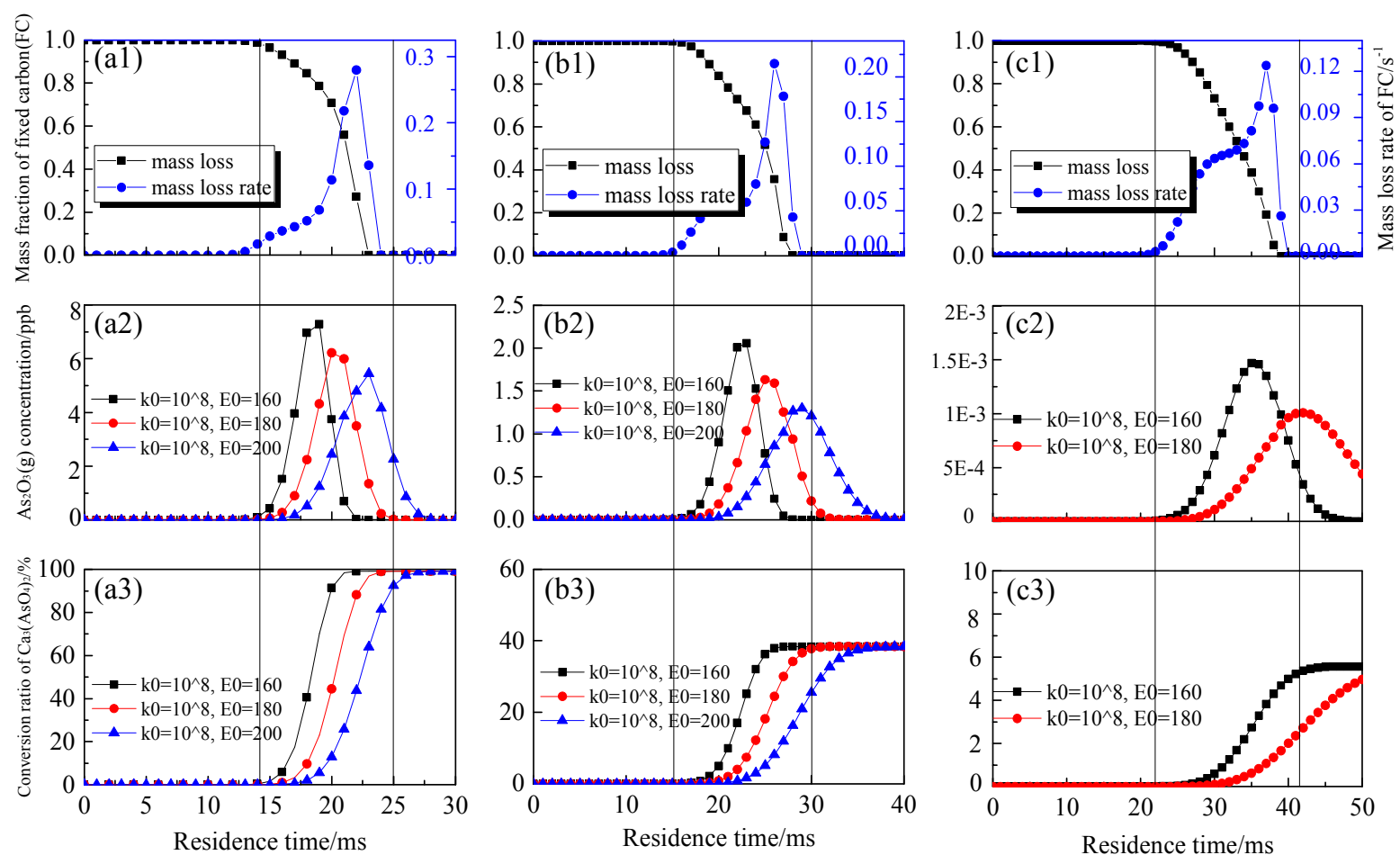

(a) KY coal at $2473 \mathrm{~K}$
(b) KY coal at $2173 \mathrm{~K}$
(c) KY coal at $1773 \mathrm{~K}$

Figure 9. Determination of the frequency factor and activation energy of $\mathrm{R} 15\left(\mathrm{Ca}_{3}\left(\mathrm{AsO}_{4}\right)_{2}\right.$ decomposition) 